\title{
ANÁLISE EXPERIMENTAL E VALIDAÇÃO DE CURVAS BIMODAIS DE RETENÇÃO DE ÁGUA NO SOLO PARA SOLOS ARENO-ARGILOSOS RESIDUAIS DA FORMAÇÃO ITAQUERI EM SÃO CARLOS - SP
}

\author{
EXPERIMENTAL ANALYSIS AND VALIDATION OF BIMODAL WATER RETENTION CURVES \\ IN THE SOIL FOR RESIDUAL SANDY CLAY SOILS OF THE ITAQUERI FORMATION IN SÃO \\ CARLOS - SP
}

\section{Daniel de Lima Nascimento SÍRIO ${ }^{1}$, Ademir Paceli BARBASSA ${ }^{1}$, Lázaro Valentim ZUQUETTE ${ }^{2}$}

${ }^{1}$ Universidade Federal de São Carlos (UFSCar), Centro de Ciências Exatas e de Tecnologia, Departamento de Engenharia Civil, Programa de Pós Graduação em Engenharia Civil. Rodovia Washington Luiz, KM 235. Monjolinho. São Carlos, SP - Brasil. E-mails: danielsirio@professor.uema.br; barbassa@ufscar.br

${ }^{2}$ Universidade de São Paulo, Escola de Engenharia de São Carlos (USP-EESC), Departamento de Geotecnia. Av. Trabalhador São Carlense, 400. São Carlos, SP - Brasil. E-mail: lazarus1@sc.usp.br

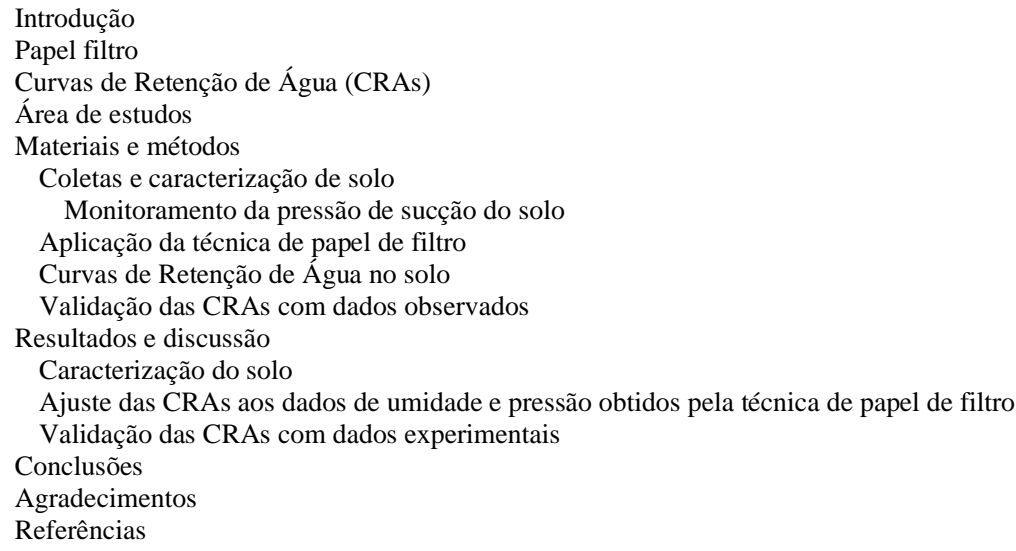

RESUMO - Esse estudo experimental obteve parâmetros para validar e ajustar quatro modelos de curva de retenção da água no solo (CRA) presentes na literatura. O experimento foi realizado no solo do campus da Universidade Federal de São Carlos, Estado de São Paulo, utilizaram-se tensiômetros para monitorar a sucção matricial do solo e o conteúdo de água em diferentes profundidades. Amostras de solo foram coletadas para construir as CRAs por meio de três técnicas de calibração de papel filtro Whatman $n^{\circ} 42$ e assim obter a relação suç̧ão matricial por umidade do solo. Os modelos de CRA foram utilizados para ajustar os valores de teor de água segundo a proposta de CRA bimodais. O experimento foi validado em laboratório medindo-se a umidade das amostras em cada profundidade, obtidas em datas diferentes e então correlacioná-las com os respectivos valores de pressão de sucção obtidas no instante de cada amostragem. O modelo de CRA de van Genuchten com restrição de Mualem e calibração de papel filtro de Chandler e outros, foi o que obteve melhor ajuste na representação da dinâmica da água no perfil em termos dos coeficientes globais: R², Nash-Sutcliffe, EAPM e RMSE.

Palavras-chave: Curvas bimodais de retenção de água no solo. Papel filtro de contato. Tensiômetro. Sucção matricial.

ABSTRACT - This experimental study obtained parameters to validate and adjust four models of soil water retention curve (SWRC) present in the literature. The experiment was performed in the soil of the campus of the Federal University of São Carlos, State of São Paulo, using tensiometers to monitor soil matrix suction and water content at different depths. Soil samples were collected to build the SWRCs using three Whatman No. 42 filter paper calibration techniques to obtain the matrix suction by soil moisture ratio. The SWRC models were used to adjust the water content values according to the bimodal SWRC proposal. The experiment was validated in the laboratory by measuring the moisture of the samples at each depth, obtained at different dates, and then correlating them with the respective suction pressure values obtained at the time of sampling. van Genuchten's Mualem-restricted SWRC model and filter paper from Chandler and others, obtained the best fit in representing the water dynamics in the profile in terms of the global coefficients: $\mathrm{R}^{2}$, Nash-Sutcliffe, EAPM and RMSE.

Keywords: Soil water retention curves. Contact filter paper. Tensiometer. Matrix suction.

\section{INTRODUÇÃO}

O fenômeno de infiltração de água no solo deve ser entendido como a transmissão de água em um espaço poroso, num dado intervalo de tempo, dentro dos interstícios de um ambiente de características heterogêneas (matriz do solo) e que contêm ar, água e componentes do solo. Para entender o processo de infiltração e dinâmica da água no solo devem-se levar em conta as dimensões dos poros do solo e sua distribuição ao longo da profundidade e como são caracte- 
rizadas e distinguidas a interações água-ar-solo. Essas interações junto à distribuição e tamanho dos poros que darão e determinarão o modo pelo qual a água infiltrada é retida no solo ou escoada no interior do solo. A retenção de água no solo afeta de forma direta e inversamente proporcional a velocidade do escoamento da água no interior do solo e suas direções de escoamento, que por sua vez, determinam quanta água será transportada para o interior do solo, qual a parcela será evaporada ou transpirada, e também, aquela que será retida por adsorção e preenchimento dos seus espaços vazios.

O solo é um material sólido e poroso, que abriga em seus poros, quantidades variáveis de uma solução aquosa de vários eletrólitos e outros componentes, denominada solução do solo e de uma solução gasosa composta praticamente de $\mathrm{N}_{2}, \mathrm{O}_{2}$, vapor d'água, $\mathrm{CO}_{2}$ e pequenas quantidades de outros gases (Hillel, 1980) e, comumente presentes na parte sólida ou matriz do solo, estão diversas partículas minerais de diferentes tamanhos e substâncias orgânicas (Reichardt, 1996). A quantidade de material orgânico presente no solo, resultante da atividade biológica e cuja produção pode ser intensa ou moderada de matéria orgânica, faz com que a retenção da água no solo seja maior proporcionalmente à sua concentração, de modo que quanto maior a decomposição, perda ou transformação de componentes minerais, mais produtivos biologicamente os solos e consequentemente, mais úmidos (Libardi, 1995; Reichardt, 1996).Quando o espaço poroso está totalmente cheio de água, o solo é chamado de solo em condições saturadas. Por outro lado, um solo não saturado é aquele cujo espaço poroso está parcialmente cheio de água e parcialmente cheio de ar. $\mathrm{O}$ ar só deverá entrar para substituir a água no espaço poroso se parte de seu volume livre e não adsorvido for retirado, resultando numa formação de interfaces ar-água pelos processos de retenção da água pela matriz do solo (Roth, 2011).

Segundo Libardi (1995) e Reichardt (1996) existem basicamente dois processos que explicam a retenção da água pelos solos ao afirmarem que no primeiro, a retenção ocorre nos microporos dos agregados e pode ser ilustrada pelo fenômeno da capilaridade, o qual está sempre associado a uma interface curva arlíquido. No entanto, o solo é formado por uma composição irregular de poros e canais em sua matriz o que, evidentemente, complica a descrição do estado da água no solo; no segundo processo, a retenção ocorre na superfície dos sólidos do solo como filmes presos a ela, pelo processo de adsorção (Libardi, 1995). São três os mecanismos principais propostos para explicar esta adsorção da água sobre as superfícies sólidas como afirma Libardi (1995), e são eles: Primeiro, a natureza dipolar das partículas de água são atraídas para a superfície dos minerais de argila carregadas negativamente devido à substituição isomórfica de cátions; segundo, os pares de elétrons não compartilhados do átomo de oxigênio das moléculas de água podem ser eletricamente atraídos a cátions trocáveis que podem estar adsorvidos sobre a superfície da argila e, por último as moléculas de água podem ainda ser atraídas às superfícies sólidas pelas forças de London-van der Waals.

Libardi (1995) e Hillel (1980) reforçam que no caso da adsorção, a película de água adsorvida às superfícies dos sólidos do solo possui, com o resultado destas forças de adsorção, uma energia potencial extra, uma vez que se se afastar uma determinada porção dessa película a uma distância dentro do raio de ação destas forças, ela voltará à posição original realizando um trabalho. Portanto, podem-se dizer que existem dois processos principais que operam na matriz do solo para a retenção da água: as forças capilares e as forças de adsorção, as quais, juntas, são chamadas de forças mátricas e dão origem ao potencial mátrico (Libardi, 1995; Reichardt, 1996).

A infiltração e as características hidráulicas que governam o movimento e a retenção de água no solo são de suma importância no estudo da geociência, na agricultura irrigada e na mecânica dos solos (Gardner, 1956; Richards et al., 1956; Fredlund \& Rahardjo, 1993a). Nesse sentido, as Curvas de Retenção de Água no Solo (CRAs) podem ser utilizadas para todo tipo de solos e permitem avaliar indiretamente o conteúdo de água no solo, a drenagem interna e a condutividade hidráulica na zona não saturada do solo (Durner, 1992; Šimůnek et al., 2002; Gitirana Jr. \& Fredlund, 2004).

Esse comportamento hidrodinâmico, quando combinado com o monitoramento da retenção de água no solo, permite estimar os volumes armazenados e drenados no interior do solo e ainda prever os volumes infiltrados ou a serem irrigados (Hillel, 1980; Libardi, 1995; Reichardt 1996). Permeando em tal importância econô- 
mica, diversos autores vêm pesquisando como prever e modelar os meios da retenção da água no solo e em consequência disso, hoje existem diversos modelos de ajuste da CRA dos solos e outros tantos métodos para se determinar a relação entre a sucção matricial e o conteúdo de água de um solo qualquer, ou seja, esses modelos relacionam a sucção matricial $\psi$ em função da umidade volumétrica do solo $\theta$. Os modelos de ajuste da CRA mais utilizados atualmente são aqueles propostos por van Genuchten (1980), Fredlund \& Xing (1994) e Gitirana Jr. \& Fredlund (2004). No caso do modelo de van Genuchten (1980) e Fredlund \& Xing (1994) a CRA é ajustada utilizando-se os parâmetros de umidade de saturação do solo $\theta_{s}$, a umidade residual $\theta_{r}$, os valores da entrada de ar $\alpha$ nos poros e os parâmetros de ajuste de inflexão da curva " $m$ ” e “ $n$ ”. Já para o modelo de Gitirana Jr. \& Fredlund (2004), os parâmetros de ajuste desse modelo de CRA são a saturação efetiva ou grau de saturação do solo $\left(S_{e}\right)$, valores de entrada de ar ( $\psi_{b 1}$ e $\left.\psi_{b 2}\right)$ e parâmetros de ajuste da curva $d_{i}$. Em solos multiporosos, ao ajustar as CRAs, há um dado intervalo de pressão em que a umidade permanece constante e são caracterizados e denominados por platôs intermediários da curva. No entanto, para se ajustar a CRA a um modelo, se faz necessário determinar a relação entre a sucção matricial de um solo à sua umidade correspondente $\theta(\psi)$, ou seja, o teor de água é função da pressão que a matriz do solo pode exercer em seus poros para manter-se úmida. Logo, podem-se utilizar panelas de pressão que aplicam determinada pressão numa amostra de solo, causando a saída de água dos poros, para posterior pesagem dessa amostra, já com seu teor de água estabilizado, via medição direta que tem boa precisão dentro do intervalo de $1 \mathrm{kpa}$ a $10^{6}$ kpa de pressão, ou até mesmo superior dependendo da panela de pressão; podem-se utilizar também, funis de subpressão ou também chamados Funis de Haines que por meio de um tubo capilar medem-se diretamente em coluna de água a pressão de sucção, nesse caso também é medida direta, mas apenas aplicável a pequenas pressões entre 0,01 e 1 $\mathrm{kpa}$; e, por último, usam-se os papéis de filtro previamente calibrados por associações e empresas do ramo de engenharia geológica e do solo e que medem, contudo, a pressão indiretamente por meio do conteúdo volumétrico de água, em equilíbrio do contato entre o papel filtro e o solo.

Um dos principais problemas associados ao método de papel filtro é o controle de temperatura e umidade do ambiente no qual irá se realizar o ensaio. Outro fato importante e que deve ser também evidenciado é a quantidade de calibrações existentes na literatura para um mesmo tipo de papel filtro. Não obstante, devemse também validar o modelo ajustado e a calibração do papel escolhidos a realidade intrínseca do seu solo para que sejam representativos aos dados de umidade a serem analisados, ou seja, como é mais fácil medir em campo a sucção matricial de um solo em relação à medida direta de sua umidade, comumente utilizam-se tensiômetros para medir a umidade do solo. Essa medida indireta de umidade será dada por meio da medida de pressão do tensiômetro instalado no solo, que é então transformada em umidade via CRA do solo.

Um dos aspectos mais limitantes nesse caminho é a adoção da curva de retenção de água que será usada para a transformação da pressão em umidade. A existência de diversos modelos matemáticos empíricos para a elaboração da curva é um ponto que ainda demanda conhecimento sobre as limitações e aplicabilidade dos modelos. Assim, o objetivo desse trabalho foi avaliar, com base em dados de campo, a aderência de quatro modelos de CRAs às umidades e tensões obtidas pela técnica de papel de filtro, utilizando-se de três diferentes calibrações consolidadas na literatura para o papel filtro Whatman $\mathrm{n}^{\circ} 42$ e, também, verificar o efeito das diferentes calibrações do papel de filtro sobre os modelos de retenção de água obtidos por cada CRA e como validá-los e ajustá-los à realidade do monitoramento de campo por meio da comparação entre as umidades e tensões medidas diretamente no solo da área de estudos e aquelas obtidas pelos modelos de CRAs, via leitura de tensiômetros, para cada uma das calibrações de papel filtro Whatman $n^{\circ} 42$.

\section{PAPEL FILTRO}

A utilização do papel filtro para determinar as CRAs, vem ganhando espaço na ciência do solo devido a seu baixo custo em relação a outros métodos propostos, os quais utilizam placas porosas, tais como as câmaras de alta pressão e funis de subpressão. O método do papel filtro é um procedimento mais prático e ágil, necessita de uma menor infraestrutura laboratorial para ser 
desenvolvido e, certamente, é menos oneroso que os demais (Ruas Lucas, 2011; Bulut, 1996).

Apesar de sua aplicabilidade e razoável acurácia, se não for realizado devidamente, e em condições laboratoriais de temperatura e umidade controladas (Marinho \& Oliveira 2006; Bicalho et al., 2007), o método do papel filtro tem maior indução e adição de erro nos ajustes das curvas. Somado a esse fato, o método não é capaz de medir tensões muito pequenas (entre 0 e $10 \mathrm{kpa}$ ) e nem extremamente altas (acima de $10^{6} \mathrm{kpa}$ ) (ASTM, 1992), e ainda, calcula a pressão de sucção $(\psi)$ indiretamente, utilizando-se de calibrações de curvas de subpressão predeterminadas em relação à massa de água, ou umidade gravimétrica $(\theta)$, contida no papel filtro no instante do equilíbrio entre $\psi$ e $\theta$ (Bicalho et al., 2007). Segundo Marinho \& Oliveira (2006), os papéis mais utilizados para o ensaio são o Whatman $\mathrm{n}^{\circ} 42$, o Schleicher e Schuell n589 e o Fisher 9.54a, pois cada um deles tem uma calibração já predeterminada.

O uso do papel filtro para medir a sucção total do solo, dada pelas somas das tensões de vapor em equilíbrio com o papel, é denominado método de não contato (Lu \& Likos, 2004), mas o papel filtro pode também, ser utilizado para medir a sucção matricial do solo. No segundo caso, o papel deve permanecer em contato com o solo até o equilíbrio da fase líquida entre ambos (método de contato) (Bicalho et al., 2007).

As calibrações de papel filtro Whatman $n^{\circ} 42$ foram inicialmente estudadas por Gardner (1937) e posteriormente, em 1992, consolidadas e homologadas pela American Society for Testing and Materials (ASTM), e atualmente, são as calibrações da associação ASTM as de maior uso e razoável precisão. Posteriormente no mesmo ano, essas calibrações do papel filtro foram estudadas e modificadas por Chandler et al. (1992) que realizaram ajustes modais nas curvas, definindo novos intervalos de umidade na calibração ao utilizar os trabalhos anteriores de Fawcett e CollisGeorge (1967) e Hamblin (1981); e, mais recentemente, aquelas calibrações pesquisadas e sugeridas por Marinho \& Oliveira (2006) que determinaram outros intervalos de calibração de umidade. Quando o solo é colocado em contato com um material poroso, que possua capacidade de transmitir água, essa será transferida do solo para esse material, ou vice-versa, até que o equilíbrio entre as forças atuantes seja alcançado (Chandler \& Gutierrez, 1986). A soma dessas forças é denominada potencial total de água no solo, e estão compreendidos entre essas forças, o potencial matricial, osmótico, pneumático, gravitacional, de pressão, etc. Entretanto, a sucção matricial é a influência da soma das forças de capilaridade e de adsorção, que atuam entre a fase líquida e a matriz do solo, que causam o fenômeno de retenção (Hillel, 1980).

A sucção matricial indica a pressão negativa em relação à pressão do ar atmosférico exercida pelo solo na água presente na matriz do solo (Richards, 1965). Nas panelas de pressão, no estado de equilíbrio das placas porosas, os potenciais matriciais da água no solo e no material poroso igualam-se, apesar de as respectivas umidades serem diferentes e o conteúdo de água é medido diretamente em relação à pressão aplicada pela câmara de alta pressão (Marinho \& Oliveira, 2006). No caso do papel filtro em contato, as umidades igualam-se e são convertidas em sucção por calibração para cada tipo de papel, conforme ASTM (1992) e dois outros autores - Chandler et al. (1992) e Marinho \& Oliveira (2006).

\section{CURVAS DE RETENÇÃO DE ÁGUA}

Os modelos das propriedades hidráulicas que governam a infiltração e a retenção de água e, sua consequente armazenagem e condutividade de água no solo, já estão consolidadas na literatura e têm uma enorme importância nas últimas décadas devido, sobretudo, à sua aplicabilidade na ciência do solo em diversas áreas do conhecimento (Nielsen et al., 1986).Esses modelos de infiltração e de retenção de água nos solos têm sido propostos e estudados na literatura, para as mais diversas aplicações (hidrológica, hidrogeológica, geotécnica, de comportamento e dinâmica da água, consumo e produção agrícola, etc.) (Gardner, 1937; Childs \& Collins-George, 1950; Brooks \& Corey, 1964; Farrel \& Larson, 1972). Os modelos numéricos empíricos propostos na literatura, que relacionaram $\psi$ e $\theta$ como uma função matemática analítica, utilizam em sua maioria, a distribuição de poros na matriz do solo e ou o grau de saturação efetiva $\left(S_{e}\right)$ para seus ajustes. Suas relações foram progressivamente estudadas desde meados do século XIX, sendo:

$$
S_{e}(\%)=\frac{\left(\theta-\theta_{r}\right)}{\left(\theta_{s}-\theta_{r}\right)}
$$


Onde, $S_{e}$ é adimensional; $\theta$ é a umidade relativa do solo em $\mathrm{cm}^{3} \cdot \mathrm{cm}^{-3}$; $\theta_{r}$ é a umidade residual em $\mathrm{cm}^{3} \cdot \mathrm{cm}^{-3} ; \theta_{s}$ é a umidade na saturação em $\mathrm{cm}^{3} \cdot \mathrm{cm}^{-3}$.Os modelos propostos nas últimas duas décadas com boa precisão e facilmente aplicáveis - além de bastante utilizados - são os de van Genuchten (1980) e Fredlund \& Xing (1994). Tratam-se de equações matemáticas propostas para a determinação da condutividade hidráulica dos solos, a partir de parâmetros ajustados de acordo com o tipo de distribuição de poros e tortuosidade do solo.

A mais famosa delas é a de van Genuchten (1980) (Equação 2), que foi obtida empiricamente e possui três parâmetros de ajuste das CRAs unimodais, que são " $\alpha$ ", cujo valor se define como o módulo da força que determina a entrada de ar e a saída de água nos poros na matriz do solo e está relacionada com o tamanho e com a distribuição dos poros no solo; e, os parâmetros “ $m$ ” e “" $n$ ” (adimensionais), que estão relacionados com a posição do ponto de inflexão e a tangente por esse ponto, respectivamente:

$$
S_{e}=\left(1+|\alpha \psi|^{n}\right)^{m}
$$

Onde, “ $\alpha$ ” (1/metro), “ $m$ ” e “ $n$ ” são coeficientes adimensionais e maiores que 0 e $\psi$ é o módulo da pressão de sucção em kpa.

A Equação 2 caracteriza-se por apresentar duas assíntotas relacionadas aos conteúdos de água no solo correspondentes à saturação e ao conteúdo residual, e um ponto de inflexão entre os platôs (saturação e residual), o qual é dependente dos atributos do solo, sendo a sua forma e inclinação reguladas por parâmetros empíricos de ajuste do modelo e que estão relacionados às características texturais e estruturais do solo (van Genuchten, 1980; Dexter, 2008; Carducci et al., 2010). Porém, os usos desses ajustes para solos com diferentes características de porosidade podem subestimar o conteúdo de água no solo, porquanto forçosamente, obriga a curva a um ajuste unimodal num intervalo de pressões mínimas (próximo à saturação) a máximas (umidade residual) (Durner, 1994; Gerke \& van Genuchten, 1993a).

$\mathrm{O}$ uso do ajuste uni-modal em alguns solos tende a subestimar o conteúdo de água próximo à saturação e no intervalo de porosidade drenável, bem como, superestimá-lo perto da umidade residual, implicando uma necessidade de ajuste bi ou trimodal dos modelos, com um ajuste para as condições próximas da saturação, um segundo para o intervalo de umidades médias de sucção nos mesoporos e um terceiro próximo à umidade residual (Mallants, 1997).

A Equação de van Genuchten (1980) foi modificada por Carducci et al. (2010) e denominada pelos autores como Duplo van Genuchten (DVG). Esses autores propuseram um modelo de obtenção de CRAs bimodais para solos da região de Cerrado brasileiro, já que esses solos têm razão elevada de macro e microporos em relação à sua quantidade de mesoporos. O estudo foi realizado com 40 amostras de Cerrado brasileiro em que o modelo se ajustou com muito boa aproximação aos dados obtidos em panela de pressão por Carducci et al. (2010), que obtiveram coeficientes de determinação $\left(\mathrm{R}^{2}\right)$ acima de 0,9 , sendo:

$$
\theta=\theta_{r}+\frac{\theta_{p}-\theta_{r}}{\left[1+\left(\alpha_{t} \psi\right)^{n_{t}}\right]^{m_{t}}}+\frac{\theta_{s}-\theta_{p}}{\left[1+\left(\alpha_{e} \psi\right)^{n e}\right]^{m_{e}}}
$$

Onde, $\theta_{p}\left(\mathrm{~cm}^{3} \cdot \mathrm{cm}^{-3}\right)$ é a umidade no platô assintótico intermediário da curva; $\alpha_{\mathrm{e}}$ e $\alpha_{\mathrm{t}}$ (1/metro) correspondem a parâmetros que conferem dupla porosidade, um da estrutura do solo (agregados ou macroporos) e outro, da textura do solo (microporos), respectivamente; “ $m_{\mathrm{e}}$ ”, " $n_{\mathrm{e}}$ ", “ $m_{\mathrm{t}}$ ” $\mathrm{e}$ " $n_{\mathrm{t}}$ ” são os parâmetros de ajuste de curvatura do modelo, os dois primeiros, do platô assintótico de saturação ao intermediário, e os dois últimos, entre o platô intermediário e o residual. As premissas da aplicação da equação de van Genuchten (1980) consideram a água e os solos incompressíveis, o potencial de pressão na zona saturada nulo e as condições de isotropia no solo. Fredlund \& Xing (1994) também propuseram um modelo matemático estatístico de ajuste de curvas de retenção para predizer a permeabilidade dos solos. Para esses dois últimos autores, a base das frequências de distribuição de poros no solo, não depende da $\theta_{r}$ para ser ajustada, mas possui uma função de correção $C(\psi)$ que utiliza a pressão de sucção da umidade residual $\left(\psi_{r}\right)$, como se segue

$$
\begin{gathered}
\theta=C(\psi) \frac{\theta_{s}}{\left\{\ln \left[\left(e+(\psi / \alpha)^{n}\right)\right]\right\}^{m}} \\
C(\psi)=\frac{-\ln \left(1+\psi / \psi_{r}\right)}{\ln \left[1+\left(1.000 .000 / \psi_{r}\right)\right]}+1
\end{gathered}
$$

Onde, “e” é o número natural (2,718281...). Anos mais tarde, Gitirana Jr. \& Fredlund (2004) propuseram outro método que relaciona $\psi \operatorname{com} S_{e}$ ao invés de $\theta$ e que prevê um ajuste bimodal para o ajuste das CRAs sem dependência entre 
parâmetros. Segundo os autores, as curvas bimo-dais são descritas por quatro hipérboles e que o modelo atendeu muito bem às características de solos argilosos brasileiros

$$
S e=\frac{S_{1}-S_{2}}{1+\left(\psi / \sqrt{\psi_{b 1} \cdot \psi_{r 1}}\right)^{d_{1}}}+\frac{S_{2}-S_{3}}{1+\left(\psi / \sqrt{\psi_{b 2} \cdot \psi_{r 1}}\right)^{d_{2}}}+\frac{S_{3}-S_{4}}{1+\left(\psi / \sqrt{\psi_{b 2} \cdot \psi_{r 2}}\right)^{d_{3}}}+S_{4}
$$

Onde, $S_{1}, S_{2}, S_{3}$ e $S_{4}$ são os graus de saturação para as quatro hipérboles em percentagem; $\psi_{b 1} \mathrm{e}$ $\psi_{\mathrm{b} 2}>0$ e são valores de entrada de ar nos poros em kpa; $\psi_{r 1}$ e $\psi_{r 2}$ são as pressões nos platôs intermediário e residual, respectivamente em kpa e, $d_{1}, d_{2}$ e $d_{3}$ estão relacionados à curvatura das hipérboles e são chamados pelos autores de fatores de ponderação (adimensionais). Devido ao arranjo estrutural, à composição químicomineralógica e à sua estreita relação com o grau de intemperismo, os solos tropicais lateríticos apresentam comportamento hidrodinâmico singular, pois apresentam elevada porosidade, distribuída entre os agregados (macroporosidade) e, no interior desses, outra estrutura de microporos (microporosidade), que lhes confere uma estrutura bimodal de retenção de água nos solos (Camapum de Carvalho et al., 2012).

Segundo Carducci et al. (2010), os solos de cerrado apresentam elevada porosidade drenável e um elevado volume de poros com diâmetro extremamente pequeno, mas não apresentam volume de poros intermediários representativo. Devido às elevadas forças de capilaridade e adsorção da água higroscópica nesses microporos, boa parte da água fica retida em seu interior e não se torna disponível ao consumo das plantas (Reichardt, 1996; Giarola et al., 2002).

A dupla porosidade confere dupla permeabilidade a esses solos, que consiste basicamente em duas regiões de interação, cujos comportamentos se dão em diferentes intervalos de valores de $\psi$. $\mathrm{Na}$ primeira, representada por pressões pequenas e mais próximas da saturação, a permeabilidade é maior e ocorre entre os agregados do solo com diâmetros maiores (macroporos ou fraturas), menor tensão superficial da água e ângulo de ataque entre as moléculas de água e solo, o que leva a uma menor força de retenção. $\mathrm{Na}$ segunda, há uma hidrodinâmica dentro dos microporos ocasionada por descontinuidades na fase líquida, diâmetro de poros muito pequenos, aumento da tortuosidade, maior tensão superficial e, consequentemente, a
(Camapum de Carvalho et al., 2012), nos quais, as relações entre os teores de água e pressões de sucção devem variar num intervalo de 0 a $10^{6}$ kpa e é descrita como:

ocorrência de diminuição da permeabilidade e uma força maior de retenção (Hillel, 1980; Libardi, 1995; Šimůnek \& van Genuchten, 2008; Roth, 2011).

Expressões preditivas para a condutividade hidráulica dos solos podem ser combinadas de acordo com a distribuição e tamanho dos poros no solo (Dourado Neto et al., 2011). As equações consolidadas na literatura que combinam distribuição e tamanhos dos poros na matriz do solo são de Burdine (1953) e Mualem (1976) para a condutividade hidráulica relativa de solos não saturados. De acordo com Vereecken (1995), para cada um dos autores os modelos se diferem na maneira como os raios dos poros são estimados e existe uma relação entre os parâmetros de ajustes “m” e "n”. Para os modelos de Mualem (1976) $\mathrm{m}=1-1 / \mathrm{n}$ e para Bourdine (1953), $m=1-2 / n$ são respectivamente representadas pelas Equações 7 e 8 .

$$
\begin{aligned}
& \theta=\theta_{r}+\frac{\theta_{p}-\theta_{r}}{\left[1+\left(\alpha_{t} \psi\right)^{n_{t}}\right]^{1-1 / n_{t}}}+\frac{\theta_{s}-\theta_{p}}{\left[1+\left(\alpha_{e} \psi\right)^{n e}\right]^{1-1 / n_{e}}} \\
& \theta=\theta_{r}+\frac{\theta_{p}-\theta_{r}}{\left[1+\left(\alpha_{t} \psi\right)^{n_{t}}\right]^{1-2 / n_{t}}}+\frac{\theta_{s}-\theta_{p}}{\left[1+\left(\alpha_{e} \psi\right)^{n e}\right]^{1-2 / n_{e}}}
\end{aligned}
$$

As relações preditivas entre “m” e " $n$ " expressas como uma função de dependência já foram avaliadas por diversos autores na literatura tais como Dourado Neto et al. (2011), Cornelis et al. (2005), Khaleel \& Relyea (1995), Yates et al. (1992) e outros.

As equações preditivas demonstraram que podem ser formuladas em termos de funções hipergeométricas, mas que o tempo de resolução desses parâmetros para os modelos de Bourdine ou Mualem são bastante morosas e, se necessário, precisam ser avaliadas empiricamente posto que, de certa forma, inicialmente o uso da independência dos parâmetros de forma experimental torna mais fácil a interpretação de qual equação preditiva se adequa melhor a realidade do solos que estão em avaliação (Dourado Neto et al. 2011). 


\section{ÁREA DE ESTUDOS}

As amostras retiradas e os tensiômetros instalados estão localizados na Universidade Federal de São Carlos (UFSCar), na cidade de São Carlos - SP, Brasil, dentro de um sistema de drenagem compensatória construída em escala real que promove a recarga artificial de água pluvial no solo, denominada filtro-valatrincheira de infiltração (FVT) cuja pesquisa vem sendo realizada, monitorada e avaliada desde 2010, por diversos pesquisadores.

São Carlos é um município localizado no interior do estado de São Paulo, na região CentroLeste do Estado (Figura 1). A área do município tem cerca de $1.140 \mathrm{~km}^{2}$ (Gonçalves, 1986) e elevação média de $860 \mathrm{~m}$. A pluviosidade média local varia em torno de $1.500 \mathrm{~mm}$ por ano e a temperatura varia entre $11^{\circ} \mathrm{C}$ e $16^{\circ} \mathrm{C}$ entre final de maio e meados de agosto e entre $17^{\circ} \mathrm{C}$ e $24^{\circ} \mathrm{C}$ no resto do ano. A cidade é um importante polo industrial e agrícola da região e é servida por rodovias e ferrovias, além de ser um polo tecnológico e possuir diversas universidades. A maior parcela do município está localizada sobre solo arenoso residual da Formação Itaqueri e área de recarga do Aquífero Guarani (Pons, 2006). O solo estudado e monitorado onde se localiza o conjunto de tensiômetros, são denominados como solos residuais da Formação Itaqueri, - que é um subgrupo do Grupo Bauru - e possuem textura areno-argilosa característicos da região de cerrado de São Carlos.

Os solos de cerrado são geralmente muito intemperizados e apresentam baixa fertilidade natural, contrastando com a elevada estabilidade dos agregados (Carducci et al., 2010). Em termos pedológicos, o solo é denominado como Latossolo Vermelho-Amarelo Laterítico Distrófico sobre o qual se localiza a maior parcela do núcleo urbano do município de São Carlos (Gonçalves, 1986).

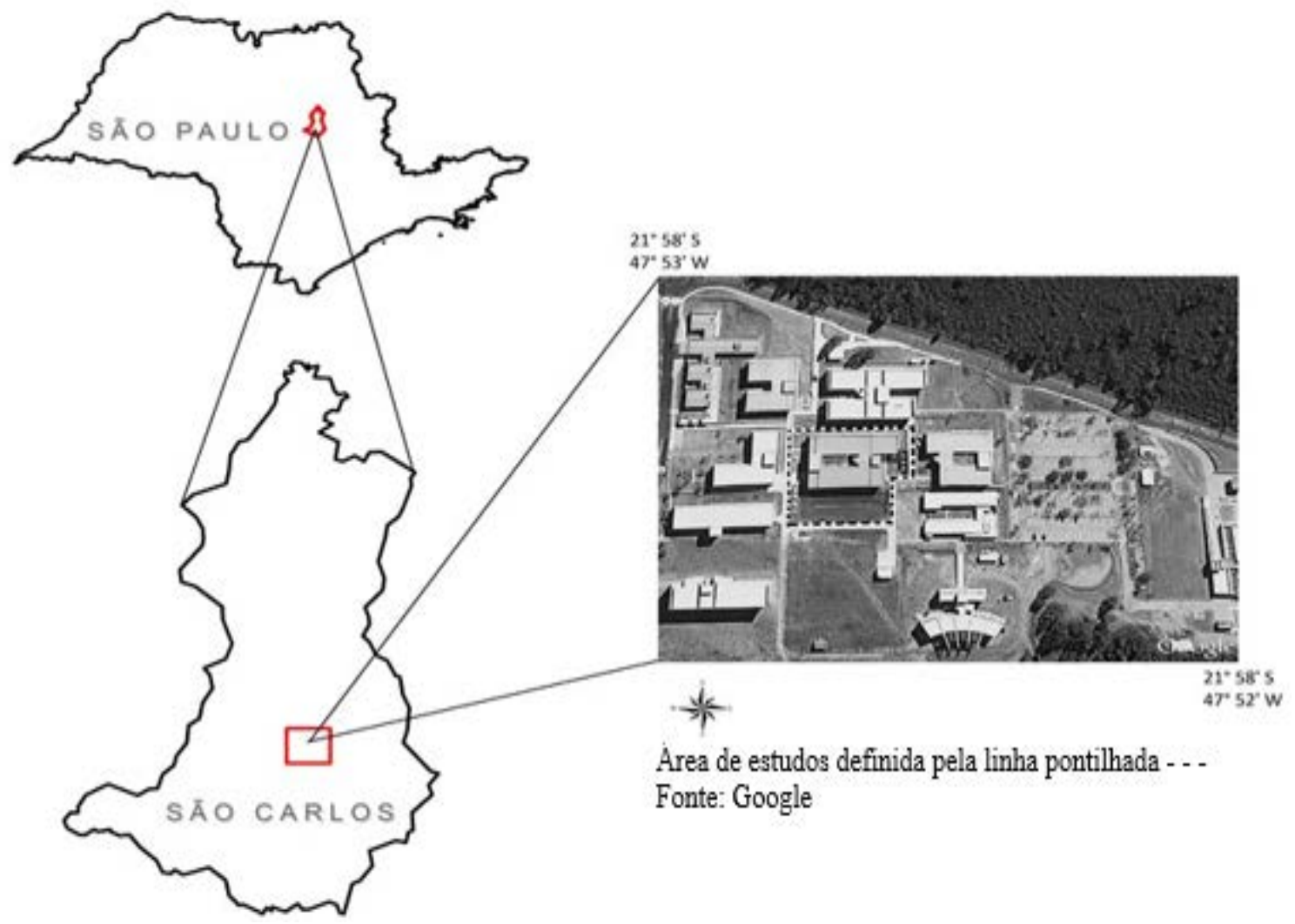

Figura 1 - Mapa de localização da área de estudos.

\section{MATERIAIS E MÉTODOS}

A pesquisa fez-se por meio da caracterização do solo local, monitoramento da tensão matricial em campo, análises de amostras de solo em laboratório, ajustes dos modelos de CRA aos dados obtidos por técnica de papel de filtro, e finalmente, na verificação dos resultados obtidos com as CRAs com as umidades e as tensões observadas em campo. Dessa forma, geraram-se 48 modelos distintos de CRAs (4 modelos de CRAs, 3 equações de calibrações de papel filtro e 4 profundidades distintas) que puderam ser contrastadas com umidades do solo e pressões de 
sucção de campo. Cada relação $\theta(\psi)$ desses 48 modelos de CRAs foram comparados com as amostras retiradas as mesmas profundidades do monitoramento tensiométrico e suas respectivas medidas de umidade (realizadas em laboratório) e com as tensões matriciais medidas diretamente nos tensiômetros instalados na área de coleta. Escolheram-se, uma CRA para cada profundidade monitorada, com base na melhor representação entre os dados de umidade das amostras de solo coletadas e sua respectiva pressão de sucção de campo e as umidades calculadas pelos modelos de CRAs geradas pelo método do papel filtro. As CRAs foram ajustadas aos dados observados de umidades com erros medidos por $\mathrm{R}^{2}$, Nash-Sutcliffe, erro quadrático médio (RMSE) e erro absoluto percentual médio (EAPM).

\section{Coletas e caracterização de Solo}

Para a caracterização física do solo coletou-se de acordo com a NBR 9604 (ABNT, 1986), em quatro pontos e 5 profundidades igualmente distribuídas no sistema FVT, no mínimo 3 amostras indeformadas e 3 amostras deformadas, somando-se um total de 144 amostras. As profundidades de extração de amostras foram: superficial; 0,$10 ; 0,50 ; 1,00 ; 1,50 ; 2,00$ e 2,50 metros. Nas 72 amostras indeformadas coletadas em extratores de PVC de $5 \mathrm{~cm}$ de diâmetro e 25 $\mathrm{cm}$ de comprimento, foram realizados ensaios de índices físicos com a finalidade de se determinar a densidade seca e natural do solo, índices de vazios, porosidade, permeabilidade e grau de saturação efetivo para cada profundidade. Os ensaios foram realizados de acordo com a NBR 6457 (ABNT, 1986), que determina a separação de amostras de solo para ensaio de compactação e ensaio de caracterização. Nas amostras deformadas, foram realizados ensaios de massa específica dos grãos a partir da NBR 6508 (ABNT, 1984). O ensaio de granulometria conjunta combina métodos de sedimentação e peneiramento para determinar também partículas com diâmetro inferior a $0,075 \mathrm{~mm}$, quando o peneiramento não é suficiente para determinar partículas finas como argila e silte, de acordo com a norma NBR 7181 (ABNT, 1982b). Os dados para aplicação da técnica de papel filtro implicou na escavação de uma vala de $1,80 \mathrm{x}$ $1,80 \times 2,50 \mathrm{~m}$ para retirada de amostras indeformadas (NBR 9604, 1986). Utilizaram-se extratores de PVC de $10 \mathrm{~cm}$ de diâmetro e $30 \mathrm{~cm}$ de comprimento e usaram-se três pivôs de coleta para a retirada de três amostras de cada uma das seguintes profundidades: até $40 \mathrm{~cm}$, de 40 a 80 $\mathrm{cm}$, de 80 a $180 \mathrm{~cm}$ e de 180 a $250 \mathrm{~cm}$, totalizando 12 amostras, todas enroladas em papel filme e acondicionadas em caixa isolante térmica e levadas ao laboratório. A vala era coberta com manda geotêxtil para manter a mesma umidade do solo durante o estudo, afinal, nessa mesma vala coletaram-se amostras de solo para determinação de umidade solo diretamente concomitantemente à medida de pressão de sucção, as quais foram usadas para a validação das CRAs.

\section{Monitoramento da pressão de sucção do solo}

O monitoramento do perfil de pressão de sucção do solo foi realizado por meio de 8 tensiômetros de bulbo poroso. Os tensiômetros foram instalados na área nas profundidades de 10 $\mathrm{cm}, 30 \mathrm{~cm}, 50 \mathrm{~cm}, 80 \mathrm{~cm}, 100 \mathrm{~cm}, 150 \mathrm{~cm}, 200 \mathrm{~cm}$ e $250 \mathrm{~cm}$ de acordo com a EMBRAPA (2008) baseada nas orientações da Universidade do Estado do Kansas de julho de 1997.

\section{Aplicação da técnica de papel de filtro}

As doze amostras indeformadas retiradas para o ensaio de papel filtro foram analisadas em laboratório conforme ASTM D5298 (1992) como se segue: i) pesagem, medição do diâmetro interno, medição da altura e identificação de todos os anéis de PVC de aproximadamente 1,0cm de altura por $5 \mathrm{~cm}$ de diâmetro; ii) extração e moldagem das amostras do solo nos 3 extratores de $10 \mathrm{~cm}$ de diâmetro por $30 \mathrm{~cm}$ de profundidade, totalizando no máximo 33 anéis moldados para cada uma das diferentes profundidades; iii) saturação das amostras com água destilada e vasilhame de PVC por 24 horas; iv) cálculo da relação entre o peso em água pelo peso total de solo mais o anel, para a divisão da umidade dos anéis em 1/18 de umidade volumétrica, desde a saturação até a umidade residual; $v$ ) secagem em estufa de infravermelho ventilada até atingirem o peso calculado para, finalmente, realizar o contato com papel filtro e a embalagem dos moldes em filme de PVC; vi) Armazenamento dos moldes em contato com o papel filtro Whatman $\mathrm{n}^{\circ} 42$, devidamente embala-dos em filme de PVC por 48 horas em sala com temperatura controlada em $20^{\circ} \mathrm{C}$; vii) pesagem dos papéis filtros assim que desembalados e medidas de umidade dos papéis filtro após 4 horas em estufa; viii) transformação de umidade em pressão de sucção com as equações de calibração do papel de filtro: ASTM D5298 (1992), Chandler et al. (1992) e Marinho \& Oliveira (2006), de acordo com a tabela 1. 
Após esses procedimentos os dados obtidos foram usados para ajustar os quatro modelos de CRAs por meio da proposta de Carducci et al. (2010), ou seja, curvas bimodais segundo van Genuchten (1980) e independência de parâmetros; van Genuchten (1980) e restrição de Bourdine (1953); van Genuchten (1980) e restrição de Mualem (1976). Também foram geradas CRAs de acordo com o modelo proposto por Gitirana Jr. \& Fredlund (2004). Na tabela 1 estão as equações utilizadas para cálculo das pressões de sucção matricial utilizadas para a relação unívoca entre umidade do papel e sucção apresentada para os solos amostrados.

Tabela 1 - Autores de calibração do papel de filtro Whatman n²42 para realização do ensaio.

\begin{tabular}{|c|c|c|c|}
\hline Referência & Sucção & W(\%) & Log10 (sucção) (Kpa) \\
\hline ASTM D5298 & Total e mátrica & $W<45,3$ & $5,327-0,0779 \mathrm{~W}$ \\
\hline ASTM D5298 & Total e mátrica & $W>45,3$ & $2,412-0,0135 \mathrm{~W}$ \\
\hline Chandler et al. (1992) & Mátrica & $\mathrm{W}<47$ & $4,842-0,0622 \mathrm{~W}$ \\
\hline Chandler et al. (1992) & Mátrica & $\mathrm{W}>47$ & $6,050-2,48 \log (W)$ \\
\hline Marinho \& Oliveira (2006) & Total e mátrica & $\mathrm{W}<33$ & $4,83-0,0839 \mathrm{~W}$ \\
\hline Marinho \& Oliveira (2006) & Total e mátrica & $\mathrm{W}>33$ & $2,57-0,0154 \mathrm{~W}$ \\
\hline
\end{tabular}

\section{Curvas de retenção de água no solo}

Os modelos de CRAs foram os seguintes: a CRA de van Genuchten (1980) (Eq. 2) e independência de parâmetros e proposta sugerida por Carducci et al. (2010) (Eq. 3); van Genuchten (1980) com restrição de Bourdine (1953) (Eq. 8) e proposta sugerida por Carducci et al. (2010); van Genuchten (1980) com restrição de Mualem (1976) (Eq. 7) e proposta sugerida por Carducci et al. (2010); e, para a CRA de Gitirana Jr. \& Fredlund (2004) (Eq. 6) que já ajusta e prediz CRAs para solos de multiporosidade. A proposta sugerida por Carducci et al. (2010) baseia-se em ajustes bimodais de CRAs baseados na curva teórica S dupla exponencial de Dexter et al. (2008) para estimativas de dois pontos de inflexão de Dexter \& Bird (2001).

O modelo duplo van Genuchten proposto por Carducci et al. (2010) e o proposto por Gitirana Jr. \& Fredlund (2004) foram ajustados aos dados experimentais de retenção de água, para cada profundidade, utilizando a umidade gravimétrica média dos papéis filtro de mesma profundidade. Os dados obtidos das 4 profundidades e 3 curvas de calibração do papel de filtro foram usados para determinação dos parâmetros de 4 tipos de CRAs e os respectivos parâmetros ajustados, profundidades e CRAs são mostrados na tabela 2. O ajuste dos parâmetros foi realizado no software $\mathrm{R}^{\circledR}$ que utiliza a rotina de Gauss-Newton (R Development Core Team, 2009; Ritz \&Streibig, 2008) com base nos sistemas não lineares e ajustes de limites dos parâmetros realizados separadamente por análise hipergeométrica, para as faixas texturais no primeiro instante e depois para as faixas estruturais das CRAs pela proposta de Carducci et al. (2010) e também da proposta de Gitirana Jr. \& Fredlund (2004). A aderência das CRAs aos dados experimentais obtidos pela técnica do papel de filtro foi avaliada pelo coeficiente de determinação $\left(\mathrm{R}^{2}\right)$, pelo coeficiente de NashSucticliffe (Nash), erro quadrático médio (RMSE) e erro padrão médio (EAPM).

Tabela 2 - Profundidades de amostragem, curvas de calibração de papel de filtro e autores de CRA.

\begin{tabular}{|c|c|c|c|}
\hline $\begin{array}{c}\text { Profundidades de } \\
\text { amostragens do solo }\end{array}$ & $\begin{array}{l}\text { Autores das curvas de } \\
\text { calibração do papel } \\
\text { filtro Whatman } \mathbf{n}^{\circ} 42 \\
\end{array}$ & Autores das CRAs & $\begin{array}{l}\text { Parâmetros } \\
\text { ajustados }\end{array}$ \\
\hline Superficial a $40 \mathrm{~cm}$ & ASTM (1992) & $\begin{array}{c}\text { - vanGenuchten (1980) sem restrição } \\
\text { de parâmetros de inflexão e proposta } \\
\text { de Carducci et al. (2010) }\end{array}$ & $\begin{array}{l}\text { Os; } \theta \mathrm{p} ; \theta r ; \alpha \mathrm{e} ; \alpha \mathrm{t} ; \\
\text { me; mt; ne; nt }\end{array}$ \\
\hline 40 a $100 \mathrm{~cm}$ & Chandler et al. (1992) & $\begin{array}{c}\text { - vanGenuchten (1980) com restrição } \\
\text { de Burdine (1953) e proposta de } \\
\text { Carducci et al. (2010) }\end{array}$ & $\begin{array}{c}\theta s ; \theta p ; \theta r ; \alpha \mathrm{e} ; \alpha \mathrm{t} ; \\
\text { ne; nt }\end{array}$ \\
\hline 100 a $180 \mathrm{~cm}$ & $\begin{array}{l}\text { Marinho \& Oliveira } \\
\text { (2006) }\end{array}$ & $\begin{array}{c}\text { - vanGenuchten (1980) com restrição } \\
\text { de Mualem (1976) e proposta de } \\
\text { Carducci et al. (2010) }\end{array}$ & $\begin{array}{c}\theta s ; \theta p ; \theta r ; \alpha \mathrm{e} ; \alpha \mathrm{t} ; \\
\text { ne; nt }\end{array}$ \\
\hline 180 a $250 \mathrm{~cm}$ & & - Gitirana Jr. \& Fredlund (2004) & $\begin{array}{c}\text { S1; S2; S3; } \psi \mathrm{b} 1 ; \\
\psi \mathrm{b} 2 ; \psi \mathrm{r} 1 ; \psi \mathrm{r} 2 ; \mathrm{d} 1 \mathrm{~d} 2 \\
\mathrm{~d} 3\end{array}$ \\
\hline
\end{tabular}


Validação das CRAs com dados observados

Para a verificação e validação das CRAs foi necessário realizar a comparação dos valores de umidades "teóricas" obtidas pelas CRAs com os valores reais de campo. Esses ensaios laboratoriais foram feitos em seis diferentes datas em que foram extraídas amostras de solo da área nas mesmas profundidades em que os tensiômetros estavam medindo tensão matricial $(10 \mathrm{~cm} ; 30 \mathrm{~cm}$; $50 \mathrm{~cm} ; 80 \mathrm{~cm} ; 100 \mathrm{~cm} ; 150 \mathrm{~cm} ; 200 \mathrm{~cm} ; 250 \mathrm{~cm}$ ). As amostras retiradas foram levadas imediatamente ao laboratório para verificação entre as umidades reais do solo e as umidades indiretas de umidade dadas pelas CRAs por meio de leituras dos tensiômetros instalados na área. Em cada data registraram-se as leituras dos tensiômetros e coletaram-se amostras de solo nas mesmas profundidades, ou seja, oito amostragens para as seis datas, totalizando 48 amostragens. $\mathrm{Na}$ sequência, calcularam-se os erros entre as umidades das CRA se as umidades de campo por meio do $\mathrm{R}^{2}$, Nash, RMSE e EAPM para eleger as CRAs mais representativas em cada uma das profundidades do solo do FVT.

\section{RESULTADOS E DISCUSSÃO}

\section{Caracterização do solo}

Apresentam-se na tabela 3 os valores médios dos pontos amostrados na área dos valores obtidos dos índices de vazios, porosidade e intervalos de porosidade obtidos, massas específicas do solo seco e natural e massa específica dos sólidos para as diferentes profundidades.

Percebe-se na tabela 3 que, os valores de porosidade nesse solo estão bastante altos devido a evolução genética por processos pedogenéticos, pois são solos com comportamento laterítico com mineralogia de quartzo, gibsita, limonita e caulinita. Os valores de porosidade aumentam cerca de $13 \%$ a partir da superfície e usando como base os intervalos de porosidade com a profundidade em todos os pontos coletados. Contudo, a diferença entre o maior e o menor valor de porosidade média não supera $12 \%$ entre a camada superficial e a profundidade máxima amostrada apresentando o maior valor na profundidade de $40 \mathrm{~cm}$ onde estão presentes as raízes e ambiente da mesofauna e micro-fauna do solo. Esse resultado representa uma moderada compactação superficial do solo e valida também, uma porosidade praticamente constante a partir da segunda camada amostrada (em torno de um valor médio de $44 \%$ ). Os resultados das análises da textura do solo foram muito similares para todas as profundidades e pontos coletados, bem como, os resultados de massa específica dos sólidos $\left(\rho_{s}\right)$ que apresentou valor médio de 2,681 g. $\mathrm{cm}^{-3}$. A textura mostrou-se predominantemente arenoargilosa e os teores de silte muito pequenos em relação aos teores de argila e areia.

Tabela 3 - Resultados dos índices físicos.

\begin{tabular}{|c|c|c|c|c|c|c|c|}
\hline \multirow[t]{2}{*}{ Amostra } & \multirow[t]{2}{*}{$\begin{array}{l}\text { Profundidade } \\
\text { (cm) }\end{array}$} & \multirow{2}{*}{$\begin{array}{c}\text { Massa } \\
\text { específica } \\
\text { natural } \\
\left(\mathrm{g} / \mathbf{c m}^{3}\right)\end{array}$} & \multirow{2}{*}{$\begin{array}{c}\begin{array}{c}\text { Massa } \\
\text { específica } \\
\text { seca }\end{array} \\
\left(\mathrm{g} / \mathrm{cm}^{3}\right) \\
\end{array}$} & \multirow[t]{2}{*}{$\begin{array}{c}\text { Índices } \\
\text { de } \\
\text { vazios }\end{array}$} & \multirow[t]{2}{*}{$\begin{array}{l}\text { Porosidade } \\
\text { média (\%) }\end{array}$} & $\begin{array}{c}\text { Porosidade } \\
\text { (\%) }\end{array}$ & $\begin{array}{c}\text { Massa } \\
\text { específica } \\
\text { dos sólidos }\end{array}$ \\
\hline & & & & & & Mín. - Máx. & $\left(\mathrm{g} / \mathrm{cm}^{3}\right)$ \\
\hline \multirow{4}{*}{$\begin{array}{c}\text { Média } \\
\text { pontos } 1,2, \\
3 \text { e } 4\end{array}$} & 0 а 40 & 1,819 & 1,590 & 0,679 & 40,45 & $39,3-41,1$ & 2,670 \\
\hline & 40 a 100 & 1,704 & 1,465 & 0,827 & 45,25 & $44,0-45,6$ & 2,676 \\
\hline & 100 a 180 & 1,761 & 1,482 & 0,816 & 44,95 & $44,2-45,4$ & 2,692 \\
\hline & 180 a 250 & 1,727 & 1,486 & 0,807 & 44,66 & $44,3-45,4$ & 2,685 \\
\hline
\end{tabular}

Segundo Soares et al. (1980), os solos residuais da Formação Itaqueri são tipicamente arenosos com teores médios de areia em torno de $45 \%$ e $35 \%$ de argila. Esses solos são formados por arenitos finos e possuem comumente profundidades menores que 30 metros. Na área de estudo, as análises do solo corroboram com Soares et al. (1980), apresentando em sua composição textural um teor médio dos quatro pontos amostrados de:
$51 \%$ a $61 \%$ de areia fina e média, de 6 a $9 \%$ de areia grossa, um terço de argila e baixo teor de silte, como apresentado na tabela 4. No ensaio textural foram realizados os ensaios de massa específica dos sólidos para um melhor ajuste da curva granulométrica feita por sedimentação e peneiramento (granulometria conjunta) e os resultados corroboram com os valores obtidos da amostragem anterior de caracterização das massas específicas do solo na área. 
Tabela 4 - Resultados da granulometria conjunta e massa específica dos sólidos $\left(\rho_{s}\right)$.

\begin{tabular}{|c|c|c|c|c|c|c|c|c|}
\hline \multirow{3}{*}{ Amostras } & \multirow{3}{*}{$\begin{array}{l}\text { Profundidade } \\
\text { (cm) }\end{array}$} & \multicolumn{6}{|c|}{ Composição granulométrica } & \multirow{3}{*}{$\frac{\rho_{\mathrm{s}}\left(\mathrm{g} / \mathrm{cm}^{3}\right)}{\text { Mín-Máx }}$} \\
\hline & & \multirow[b]{2}{*}{ Argila } & \multirow[b]{2}{*}{ Silte } & \multicolumn{3}{|c|}{ Areia } & \multirow{2}{*}{$\begin{array}{c}\rho_{\mathrm{s}} \\
\left(\mathrm{g} / \mathrm{cm}^{3}\right. \\
)^{2} \\
\end{array}$} & \\
\hline & & & & Fina & Média & Grossa & & \\
\hline \multirow{6}{*}{$\begin{array}{c}\text { Média } \\
\text { pontos } 1,2,3 \\
\text { e } 4\end{array}$} & 10 & $32 \%$ & $6 \%$ & $21 \%$ & $35 \%$ & $6 \%$ & 2,672 & $2,670-2,676$ \\
\hline & 50 & $35 \%$ & $5 \%$ & $21 \%$ & $32 \%$ & $8 \%$ & 2,672 & $2,671-2,676$ \\
\hline & 100 & $31 \%$ & $7 \%$ & $25 \%$ & $32 \%$ & $6 \%$ & 2,678 & $2,672-2,680$ \\
\hline & 150 & $34 \%$ & $6 \%$ & $22 \%$ & $31 \%$ & $8 \%$ & 2,678 & $2,670-2,679$ \\
\hline & 200 & $36 \%$ & $4 \%$ & $18 \%$ & $35 \%$ & $7 \%$ & 2,682 & $2,677-2,693$ \\
\hline & 250 & $34 \%$ & $6 \%$ & $17 \%$ & $34 \%$ & $9 \%$ & 2,682 & $2,679-2,692$ \\
\hline
\end{tabular}

Ajuste das CRAs aos dados de umidade e pressão obtidos pela técnica de papel de filtro Apresentam-se na tabela 5 os parâmetros das 48 CRAs ajustadas no software RStudio ${ }^{\circledR}$, em que todas as CRAs alcançaram coeficientes de determinação $\left(\mathrm{R}^{2}\right)$ maiores que 0,89 quando comparadas as correlações entre as pressões e umidades geradas pela curva CRA e as umidades do papel de filtro e as pressões calculadas pelos modelos de calibração, como podem ser verificados na última coluna. Junto às informações de cada profundidade, mostrados na tabela 5, estão os dados observados de umidade de saturação $\left(\theta_{S}\right)$ e umidade residual dos anéis de solo do ensaio de papel filtro $\left(\theta_{r}\right)$ e o cálculo da umidade de saturação e umidade residual a partir da saturação efetiva do solo para as curvas de Gitirana Jr. \& Fredlund (2004). Observa-se na tabela 5 que as umidades nos platôs de saturação $\theta_{\mathrm{s}}$ e as umidades dos platôs intermediários $\theta_{p}$ aumentam com a profundidade até a penúltima camada.

As diferenças de umidades entre esses platôs são praticamente constantes e próximas de $20 \%$ em todas as profundidades, tanto para os dados experimentais quanto calculados, com exceção de Gitirana Jr. \& Fredlund (2004).

Isso ocorreu devido à leve inclinação do platô intermediário desse ajuste, fazendo com que a diferença varie entre $\psi_{\mathrm{r} 1}$ e $\psi_{\mathrm{r} 2}$ de $13 \%$ a $25 \%$. O início da faixa de variação da pressão de sucção medida em campo varia torno de 0 kpa na camada superficial, o que indica saturação, e diminui até a -55 kpa para a profundidade de $250 \mathrm{~cm}$, conforme se observa na figura 2. O final da faixa alcança $100 \mathrm{kPa}$ para todas as profundidades. Nessa faixa, tem-se a transição de umidade entre os platôs de saturação e intermediário.

Essa transição entre platôs ocorre aproximadamente entre -2 e $-20 \mathrm{kPa}$ para todas as profundidades. Na profundidade de 0 a $40 \mathrm{~cm}$, as doze CRAs apresentaram o platô intermediário com inclinação suave e quase inexistente, como pode ser observado na Figura 2. Para as outras profundidades estes platôs são bem definidos. Isso porque as variações de umidade entre os platôs de saturação e intermediário, são mais abruptas para um menor intervalo de pressão matricial nas camadas de solo a partir de $40 \mathrm{~cm}$ de profundidade. Percebe-se que nas 48 CRAs ajustadas com a calibração de Chandler et al. (1992), as pressões de sucção são superestimadas em relação àquelas com a calibração de ASTM (1992) entre o platô de saturação e o platô intermediário. Em todas as CRAs, nas calibrações ASTM (1992) as pressões de sucção são superestimadas em relação a Chandler et al. (1992) entre o platô intermediário e o residual. Finalmente, para as calibrações de Marinho \& Oliveira (2006), as pressões de sucção são subestimadas em relação a ASTM e Chandler et al. (1992) em todo intervalo de pressão.

Nota-se pela tabela 5 e pela figura 2, que o teor de umidade do platô intermediário $\theta_{p}$ cresce aproximadamente 2 vezes entre a camada superficial e a de $180 \mathrm{~cm}$.

Desse modo, pode-se justificar teores de água mais altos comumente encontradas nessas camadas do solo, dado ao fato que a pressão de sucção necessária para se retirar a umidade do platô intermediário precisa ser superior a 1000kpa.

O que se pode observar é que as CRAs mantêm um padrão tanto na saturação em relação as pressões de sucção para cada calibração, quanto na umidade residual. Na saturação as menores pressões de sucção necessárias para reduzir o teor de água é sempre menor para a calibração de Marinho \& Oliveira (2006), independente do solo estar próximo da saturação ou da umidade residual. 
Já para Chandler et al. (1992) e ASTM as pressões se alternam tanto próximas à saturação, porquanto as pressões necessárias para a calibração de Chandler et al. (1992) precisam ser um pouco maiores que as pressões da calibração ASTM para começar a se retirar água da matriz do solo, quanto, no contrário, próximo a umidade residual após o platô intermediário as pressões maiores devem ser exercidas para a calibração ASTM em relação à calibração de Chandler et al. (1992). Esses intervalos de valores são na prática bem curtos próximo à saturação variando entre 5 e 45 kpa e próximos da capacidade de campo do solo.

Tabela 5 - Parte 1: Parâmetros ajustados de 48 CRAs referentes à quatro profundidades, três calibrações de papel de filtro, quatro autores de CRA.

\begin{tabular}{|c|c|c|c|c|c|c|c|c|c|c|c|c|}
\hline \multirow{21}{*}{ 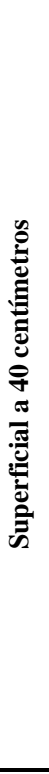 } & \multicolumn{12}{|c|}{ van Genuchten (1980) e independência de parâmetros e proposta de Carducci et al. (2010) } \\
\hline & Calibração papel filtro & $\theta_{\mathrm{s}}$ & $\theta_{\mathrm{P}}$ & $\theta_{\mathrm{r}}$ & $\alpha_{\mathrm{e}}(1 / \mathrm{m})$ & $\mathbf{m}_{\mathrm{e}}$ & $\mathbf{n}_{\mathbf{e}}$ & $\alpha_{t}(1 / m)$ & $\mathbf{m}_{\mathbf{t}}$ & \multicolumn{2}{|l|}{$\mathbf{n}_{\mathbf{t}}$} & $\mathbf{R}^{2}$ \\
\hline & ASTM D5298 & 0,405 & 0,098 & 0,017 & 0,389 & 0,171 & 2,867 & 1,99E-05 & 17,256 & \multicolumn{2}{|l|}{6,241} & 0,926 \\
\hline & Chandler et al. (1992) & 0,403 & 0,107 & 0,017 & 0,205 & 0,050 & 13,890 & $1,94 \mathrm{E}-05$ & 28,570 & \multicolumn{2}{|l|}{2,99} & 0,943 \\
\hline & Marinho \& Oliveira (2006) & 0,408 & 0,079 & 0,017 & 0,547 & 0,164 & 2,357 & 8,43E-05 & 15,234 & \multicolumn{2}{|l|}{8,401} & 0,927 \\
\hline & & \multicolumn{11}{|c|}{ van Genuchten (1980) e restrição de Bourdine (1953) e proposta de Carducci et al. (2010) } \\
\hline & Calibração papel filtro & $\theta_{\mathrm{s}}$ & $\theta_{\mathrm{P}}$ & $\theta_{\mathrm{r}}$ & $\alpha_{\mathrm{e}}(1 / \mathrm{m})$ & $m_{e}=1-2 / n_{e}$ & $\mathbf{n}_{\mathrm{e}}$ & $\alpha_{\mathrm{t}}(1 / \mathrm{m})$ & $m_{t}=1-2 / n_{t}$ & \multicolumn{2}{|c|}{$\mathbf{n}_{\mathrm{t}}$} & $\mathbf{R}^{2}$ \\
\hline & ASTM D5298 & 0,400 & 0,121 & 0,018 & 0,129 & 0,564 & 4,590 & $3,98 \mathrm{E}-05$ & 0,778 & \multicolumn{2}{|l|}{9,002} & 0,951 \\
\hline & Chandler et al. (1992) & 0,398 & 0,122 & 0,015 & 0,280 & 0,458 & 3,687 & $8,45 \mathrm{E}-05$ & 0,686 & \multicolumn{2}{|l|}{6,365} & 0,924 \\
\hline & Marinho \& Oliveira (2006) & 0,276 & 0,07 & 0,01 & 0,540 & 0,164 & 2,393 & $1,25 \mathrm{E}-04$ & 0,789 & \multicolumn{2}{|l|}{9,485} & 0,950 \\
\hline & & \multicolumn{11}{|c|}{ van Genuchten (1980) e restrição de Mualem (1976) e proposta de Carducciet al. (2010) } \\
\hline & Calibração papel filtro & $\theta_{\mathrm{s}}$ & $\theta_{\mathrm{P}}$ & $\theta_{\mathrm{r}}$ & $\alpha_{e}(1 / m)$ & $m_{e}=1-1 / n_{e}$ & $\mathbf{n}_{\mathbf{e}}$ & $\alpha_{t}(1 / m)$ & $m_{t}=1-1 / n_{t}$ & \multicolumn{2}{|c|}{$\mathbf{n}_{\mathrm{t}}$} & $\mathbf{R}^{2}$ \\
\hline & ASTM D5298 & 0,404 & 0,128 & 0,018 & 0,158 & 0,680 & 3,125 & 4,178E-05 & 0,875 & \multicolumn{2}{|l|}{8,002} & 0,956 \\
\hline & Chandler et al. (1992) & 0,398 & 0,127 & 0,015 & 0,129 & 0,824 & 5,687 & $8,450 \mathrm{E}-05$ & 0,893 & \multicolumn{2}{|l|}{9,365} & 0,942 \\
\hline & Marinho \& Oliveira (2006) & 0,404 & 0,130 & 0,020 & 0,195 & 0,702 & 3,357 & 1,84E-04 & 0,934 & \multicolumn{2}{|l|}{15,156} & 0,932 \\
\hline & & \multicolumn{11}{|c|}{ Gitirana Jr. \& Fredlund (2004) } \\
\hline & Calibração papel filtro & $S_{1}$ & $S_{2}$ & $S_{3}$ & $\psi_{\mathrm{b} 1}$ & $\psi_{\mathrm{b} 2}$ & $\psi_{\mathrm{r} 1}$ & $\psi_{\mathrm{r} 2}$ & $d_{1}$ & $d_{2}$ & $d_{3}$ & $\mathbf{R}^{\mathbf{2}}$ \\
\hline & ASTM D5298 & 0,995 & 0,440 & 0,285 & 32,067 & 19918,257 & 2,000 & 45723,756 & 3,729 & 0,685 & 9,606 & 0,989 \\
\hline & Chandler et al. (1992) & 0,998 & 0,457 & 0,282 & 4,778 & 2730,820 & 20,331 & 92411,449 & 4,325 & 0,653 & 5,406 & 0,995 \\
\hline & Marinho \& Oliveira (2006) & 0,999 & 0,405 & 0,280 & 6,164 & 2449,050 & 15,779 & 36952,257 & 2,896 & 0,690 & 12,170 & 0,993 \\
\hline & \multicolumn{12}{|c|}{ Observados: $\theta_{\mathrm{S}}=40,51 \mathrm{~cm}^{3} \cdot \mathrm{cm}^{3} ; \theta_{\mathrm{r}}=1,93 \mathrm{~cm}^{3} \cdot \mathrm{cm}^{3} ; \theta=S e .\left(\theta_{S}-\theta_{r}\right)+\theta_{\mathrm{r}} ; \mathrm{S}_{4}=0,01 \mathrm{~cm}^{3} \cdot \mathrm{cm}^{3}$} \\
\hline \multicolumn{13}{|c|}{ van Genuchten (1980) e independência de parâmetros e proposta de Carducci et al. (2010) } \\
\hline \multirow{20}{*}{ 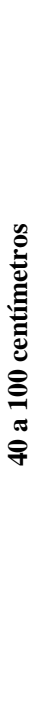 } & Calibração papel filtro & $\theta_{\mathrm{s}}$ & $\theta_{\mathrm{P}}$ & $\theta_{\mathrm{r}}$ & $\alpha_{e}(1 / m)$ & $\mathbf{m}_{\mathrm{e}}$ & $\mathbf{n}_{\mathbf{e}}$ & $\alpha_{t}(1 / m)$ & $\mathbf{m}_{\mathrm{t}}$ & $\mathbf{n}_{\mathbf{t}}$ & & $\mathbf{R}^{2}$ \\
\hline & ASTM D5298 & 0,451 & 0,165 & 0,038 & 0,275 & 0,147 & 15,246 & $2,58 \mathrm{E}-05$ & 17,256 & 6,241 & & 0,906 \\
\hline & Chandler et al. (1992) & 0,454 & 0,166 & 0,038 & 0,166 & 0,300 & 9,005 & 2,64E-05 & 40,215 & 3,750 & & 0,950 \\
\hline & Marinho \& Oliveira (2006) & 0,453 & 0,160 & 0,040 & 0,231 & 0,784 & 4,387 & 8,43E-05 & 40,234 & 6,401 & & 0,926 \\
\hline & & \multicolumn{11}{|c|}{ van Genuchten (1980) e restrição de Bourdine (1953) e proposta de Carducci et al. (2010) } \\
\hline & Calibração papel filtro & $\theta_{\mathrm{s}}$ & $\theta_{\mathrm{P}}$ & $\theta_{\mathrm{r}}$ & $\alpha_{\mathrm{e}}(1 / \mathrm{m})$ & $m_{e}=1-2 / n_{e}$ & $\mathbf{n}_{\mathbf{e}}$ & $\alpha_{\mathrm{t}}(1 / \mathrm{m})$ & $\mathbf{m}_{\mathrm{t}}=1-2 / \mathbf{n}_{\mathrm{t}}$ & \multicolumn{2}{|l|}{$\mathbf{n}_{\mathbf{t}}$} & $\mathbf{R}^{2}$ \\
\hline & ASTM D5298 & 0,452 & 0,154 & 0,037 & 0,190 & 0,564 & 4,590 & 3,78E-05 & 0,778 & 9,002 & & 0,949 \\
\hline & Chandler et al. (1992) & 0,452 & 0,156 & 0,039 & 0,135 & 0,701 & 6,687 & 8,45E-05 & 0,686 & 6,687 & & 0,946 \\
\hline & Marinho \& Oliveira (2006) & 0,450 & 0,158 & 0,040 & 0,325 & 0,467 & 3,753 & $1,54 \mathrm{E}-04$ & 0,675 & 6,156 & & 0,941 \\
\hline & & & van & nucl & (1980) & strição & Lualem & 976) e prol & sta de Ca & cci et al. & 2010) & \\
\hline & Calibração papel filtro & $\theta_{\mathrm{s}}$ & $\theta_{\mathrm{P}}$ & $\theta_{\mathrm{r}}$ & $\alpha_{\mathrm{e}}(1 / \mathrm{m})$ & $m_{e}=1-1 / n_{e}$ & $\mathbf{n}_{\mathrm{e}}$ & $\alpha_{\mathrm{t}}(1 / \mathrm{m})$ & $m_{t}=1-1 / n_{t}$ & $n_{t}$ & & $\mathbf{R}^{2}$ \\
\hline & ASTM D5298 & 0,451 & 0,138 & 0,032 & 0,154 & 0,758 & 4,126 & 3,17E-05 & 0,833 & 6,002 & & 0,947 \\
\hline & Chandler et al. (1992) & 0,450 & 0,140 & 0,032 & 0,129 & 0,814 & 5,369 & $6,45 \mathrm{E}-05$ & 0,843 & 6,365 & & 0,949 \\
\hline & Marinho \& Oliveira (2006) & 0,450 & 0,140 & 0,036 & 0,215 & 0,702 & 3,357 & 1,60E-04 & 0,934 & 15,156 & & 0,932 \\
\hline & & & & & & Gitira & $.8 \mathrm{~F}$ & nd (2004) & & & & \\
\hline & Calibração papel filtro & $S_{1}$ & $S_{2}$ & $S_{3}$ & $\psi_{\mathrm{b} 1}$ & $\psi_{\mathrm{b} 2}$ & $\psi_{\mathrm{r} 1}$ & $\psi_{\mathrm{r} 2}$ & $d_{1}$ & $d_{2}$ & $d_{3}$ & $\mathbf{R}^{\mathbf{2}}$ \\
\hline & ASTM D5298 & 1,000 & 0,346 & 0,148 & 1,833 & 20871,603 & 17,247 & 38171,93 & 4,276 & 0,459 & 9,875 & 0,949 \\
\hline & Chandler et al. (1992) & 0,999 & 0,351 & 0,164 & 3,211 & 7256,846 & 15,545 & 33125,80 & 6,520 & 0,775 & 9,255 & 0,948 \\
\hline & Marinho \& Oliveira (2006) & 0,997 & 0,228 & 0,166 & 1,001 & 7516,201 & 22,694 & 10876,28 & 2,584 & 0,999 & 4,802 & 0,948 \\
\hline & & Observ & ados: $\theta_{s}$ & $=45,4 \mathrm{cr}$ & $\mathbf{1}^{3} \cdot \mathrm{cm}^{3} ; \theta_{\mathrm{r}}=$ &, $05 \mathrm{~cm}^{3} \cdot \mathrm{cm}^{3}$ & $\theta=\operatorname{Se} .\left(\theta_{s}\right.$ & $\left.\theta_{r}\right)+\theta_{r} ; S_{4}=0$ & $\mathrm{~cm}^{3} \cdot \mathbf{c m}^{3}$ & & & \\
\hline
\end{tabular}

No entanto, próximo ao teor de água residual, as diferenças são bastante pronunciadas, já que se trata de escala logarítmica, abarcando diferenças de valores superiores a $40.000 \mathrm{kpa}$ para as camadas superficiais e aproximadamente 35.000 kpa para as outras camadas de solo, após umidades menores que $8 \%$, o que não é razoável ou recorrentes em condições naturais para esse solo.

As menores umidades volumétricas encontradas na área durante a pesquisa que vem ocorrendo a quase 9 anos, mesmo após períodos severos de estiagem não são inferiores a $11 \%$ de umidade volumétrica para esse solo. Mostram-se pelas análises gráficas (Figura 2) e paramétricas das CRAs (Tabela 5), diferenças importantes entre elas não expressas pelo coeficiente de determinação $R^{2}$, como por exemplo platôs intermediários bem definidos e constantes nas CRAs que utilizam a equação de van Genuchten (1980) e platô variável para o modelo de Gitirana 
Jr \& Fredlund (2004). Outra observação importante que se pode fazer é a forma das CRAs em função da profundidade, em que o decaimento de umidade ocorre cada vez mais rápido com variações

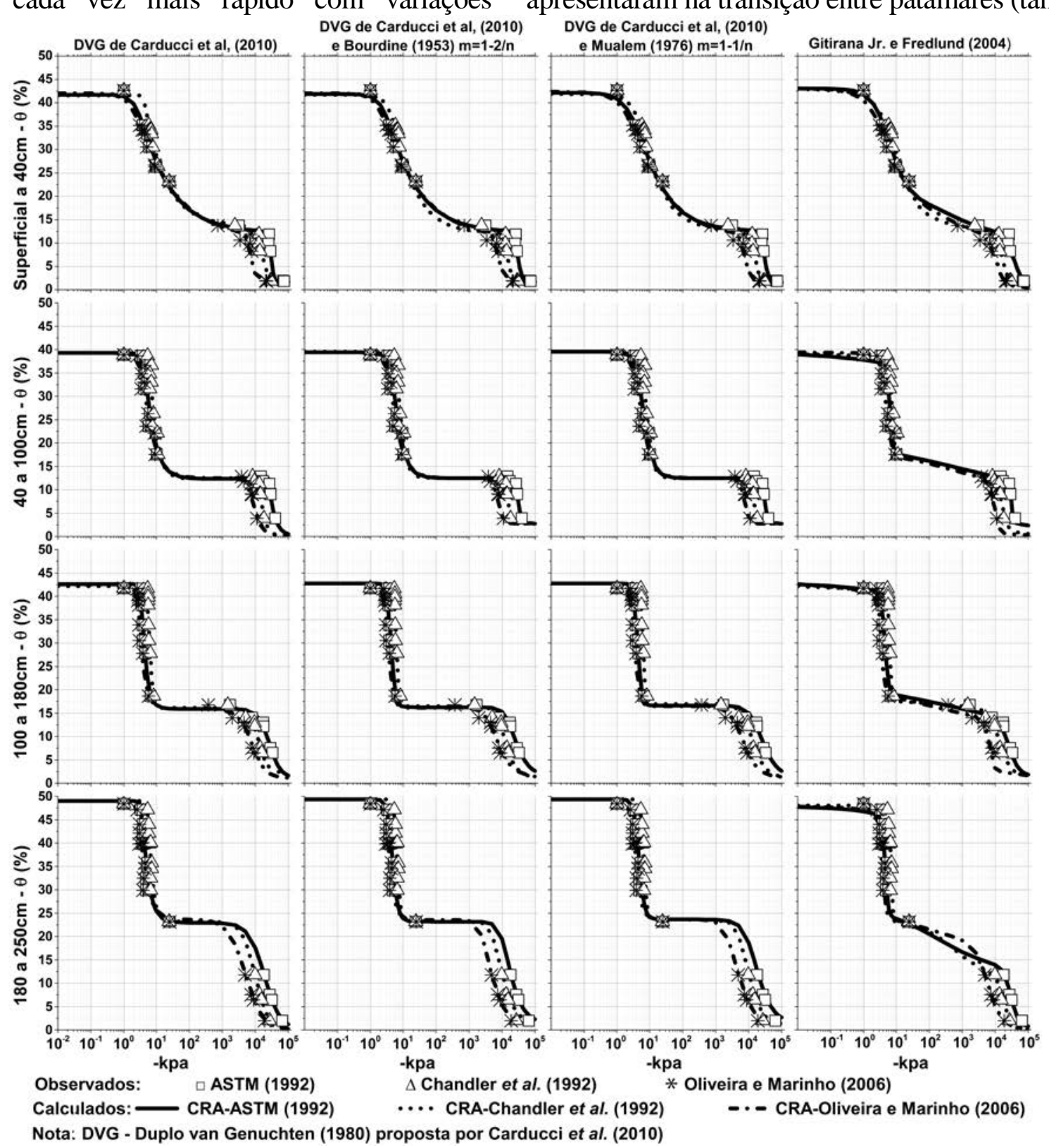

pequenas de pressão quando se aumenta a profundidade do solo. As CRAs obtidas com curvas de calibração de Marinho \& Oliveira (2006) apresentaram na transição entre patamares (tanto

Figura 2 - Curvas de sucção matricial por umidade volumétrica para três calibrações de papel filtro propostas por Chandler et al. (1992), ASTM (1992) e Marinho \& Oliveira (2006), em quatro incrementos de profundidade (linhas) e quatro diferentes modelos de CRA (colunas), três compostas pelo Duplo van Genuchten (1980) e proposta por Carducci et al. (2010), sem restrição na primeira coluna, com restrição de Bourdine (1953) na segunda coluna, com restrição de Mualem (1976) na terceira coluna e, na quarta coluna, o ajuste bimodal proposto por Gitirana \& Fredlund (2004).

de saturação e intermediário, quanto entre o intermediário e residual) pressões de sucção inferiores àquelas das CRAs obtidas a partir de Chandler et al. (1992) e ASTM (1992). Os platôs de umidade intermediários das CRAs modeladas por Gitirana Jr. \& Fredlund (2004) apresentaram pequena declividade e, consequentemente, uma queda de umidade entre os pontos de inflexão (final da curva saturação e platô intermediário e platô intermediário e início da curva de umidade residual) para todas as profundidades e calibrações de papel filtro.

As umidades calculadas pelas CRAs para as profundidades de $30 \mathrm{~cm}$ ficaram abaixo das observadas no solo local ou pelos valores calculados pelas CRAs para outras profundidades, entretanto, o $R^{2}$ entre a umidades calculadas pela CRA e as medidas nas seis datas de 0,983 , Nash de 0,252 e erro padrão de $10,72 \%$ de umidade. Apesar do erro padrão ser alto e o coeficiente de Nash ser baixo, o $\mathrm{R}^{2}$ se apresentou alto devido ao padrão de distribuição da curva de umidade para a 
profundidade de $30 \mathrm{~cm}$, apresentando sempre umidades calculadas mais baixas que as medidas.

\section{Validação das CRAs com dados experimentais}

As CRAs, que melhor representam as umidades e a pressão de sucção, foram selecionadas experimentalmente. As amostragens de solo para obtenção de umidade foram realizadas nas mesmas profundidades em que estavam instalados os tensiômetros (10, 30, 50, 80, 100, 150, 200 e 250 $\mathrm{cm})$. Obtiveram-se em laboratório 48 dados de pressão e umidade (6 datas em 8 profundidades) que variaram numa faixa de umidade volumétrica de $10 \%$ a $35 \%$. Para essas pressões as CRAs ajustadas (parâmetros da Tabela 2) obtiveram-se as respectivas umidades calculadas. Em seguida os erros entre as umidades observadas e calculadas foram medidos pelos coeficientes de determinação $\left(\mathrm{R}^{2}\right)$, de Nash-Sutcliffe, pelo erro quadrático médio e pelo valor absoluto da diferença entre as umidades em campo e aquelas determinadas pelas CRAs.

Logo, utilizou-se simultaneamente os coeficientes de Nash-Sutcliffe e o coeficiente de determinação $\mathrm{R}^{2}$, concomitantemente com os menores erros absolutos dentre os dados observados e os calculados em cada profundidade nas seis datas de coleta solo e, dessa forma, selecionaram-se uma CRA de 12 CRAs modeladas para superfície a $40 \mathrm{~cm}$ de profundidade e que melhor se ajustou, em termos dos coeficientes utilizados, uma para a profundidade de $10 \mathrm{~cm}$ e outra para a profundidade de $30 \mathrm{~cm}$, uma CRA para a amostra de $50 \mathrm{~cm}$ e dentre 12 CRAs de 40 a $100 \mathrm{~cm}$, assim, sucessivamente até a amostra de $250 \mathrm{~cm}$, ou seja, foram elegidas 8 CRAs que melhor se ajustaram ao perfil de solo estudado.

Apresentam-se na tabela 6, o resultado de correspondência entre as umidades nas profundidades amostradas e as CRAs, em que na terceira e quarta colunas, estão as melhores CRAs e curva de calibração de papel de filtro, por profundidade de amostragem.

Verifica-se que as curvas de calibração de papel filtro Whatman $\mathrm{n}^{\circ} 42$ que melhor se ajustaram ao solo local foram a de Marinho \& Oliveira (2006) e ASTM (1992), para 3 profundidades monitoradas cada e a de Chandler et al. (1992) para 2 profundidades monitoradas com os tensiômetros. No caso dos modelos de CRAs ajustados não se obtiveram um padrão e para cada caso uma CRA foi escolhida de acordo com os dados avaliados.

O maior erro absoluto entre as umidades medidas nas amostras e as calculadas pelas CRAs atingiu, em módulo, $11,07 \%$ e o menor $1,25 \%$ para as umidades das profundidades amostradas de solo, enquanto o erro médio quadrático ficou entre valores de $0,24 \%$ a $1,78 \%$. Os maiores erros foram observados para as camadas superficiais do solo aonde a umidade tem uma maior amplitude de variação, o que é esperado já que interferências de evaporação e transpiração promovidas pelas raízes são mais expressivas. A relação entre as umidades calculadas pelas CRAs de melhor representação e as umidades experimentais é mostrada na figura 3, cujo coeficiente Nash-Sutcliffe global atingiu 0,95 enquanto o $\mathrm{R}^{2}$ global 0,96 , ou seja, para o conjunto de dados gerados no perfil do solo as curvas elencadas tem boa representação do teor de água nas camadas representadas pelos modelos de calibração e de CRAs.

Tabela 6 - Curvas de retenção de água no solo escolhidas para as profundidades em que se mediram umidade e pressão nos tensiômetros.

\begin{tabular}{|c|c|c|c|c|c|c|c|}
\hline $\begin{array}{c}\text { Profundidade } \\
\text { amostragem } \\
\text { (cm) }\end{array}$ & $\begin{array}{l}\text { Profundidade } \\
\text { daCRAs }\end{array}$ & Modelo CRA & $\begin{array}{l}\text { Método de calibração de } \\
\text { papel filtro }\end{array}$ & $\mathbf{R}^{2}$ & $\begin{array}{c}\text { Nash- } \\
\text { Suctcliffe }\end{array}$ & $\begin{array}{c}\text { EAPM } \\
(\%)\end{array}$ & $\begin{array}{c}\text { RM } \\
\text { SE } \\
(\%) \\
\end{array}$ \\
\hline 10 & 0 a $40 \mathrm{~cm}$ & Gitirana Jr. \& Fredlund (2004) & Chandler et al. (1992) & 0,96 & 0,72 & 11,07 & 1,78 \\
\hline 30 & 0 a $40 \mathrm{~cm}$ & Gitirana Jr. \& Fredlund (2004) & Marinho \& Oliveira (2006) & 0,98 & 0,25 & 10,72 & 1,57 \\
\hline 50 & $40 \mathrm{~cm}$ a $100 \mathrm{~cm}$ & van Genuchten (1980) sem restrição & ASTM (1992) & 0,85 & 0,68 & 4,12 & 0,52 \\
\hline 80 & $40 \mathrm{~cm}$ a $100 \mathrm{~cm}$ & $\begin{array}{l}\text { van Genuchten (1980) com } \\
\text { restrição de Mualem (1976) }\end{array}$ & Chandler et al. (1992) & 0,88 & 0,64 & 1,32 & 0,24 \\
\hline 100 & $40 \mathrm{~cm}$ a $100 \mathrm{~cm}$ & van Genuchten (1980) sem restrição & Marinho \& Oliveira (2006) & 0,71 & 0,53 & 1,80 & 0,43 \\
\hline 150 & $100 \mathrm{~cm}$ a $180 \mathrm{~cm}$ & Gitirana Jr. \& Fredlund (2004) & Marinho \& Oliveira (2006) & 0,69 & 0,42 & 2,37 & 0,45 \\
\hline 200 & $180 \mathrm{~cm}$ a $250 \mathrm{~cm}$ & $\begin{array}{l}\text { van Genuchten (1980) com } \\
\text { restrição de Bourdine (1953) }\end{array}$ & ASTM (1992) & 0,51 & 0,14 & 1,25 & 0,84 \\
\hline 250 & $180 \mathrm{~cm}$ a $250 \mathrm{~cm}$ & $\begin{array}{l}\text { van Genuchten (1980) com } \\
\text { restrição de Bourdine (1953) }\end{array}$ & ASTM (1992) & 0,83 & 0,52 & 2,40 & 0,61 \\
\hline
\end{tabular}


A eficiência de Nash-Sutcliffe pode variar de $-\infty$ a 1 , em que valores próximos de 1 indicam uma excelente correspondência entre os dados calculados pelo modelo e os dados observados, no caso, as curvas ajustadas para 10 e $50 \mathrm{~cm}$ e que apresentaram coeficientes de Nash superiores a 0,65 ; por outro lado, se a eficiência de Nash estiver próxima de 0 isso indica que os dados calculados pelo modelo se aproximam da média dos dados observados e podem também ser utilizados com ressalvas e foi o que ocorreu com os modelos ajustados a partir de 30, 150 e $200 \mathrm{~cm}$.

Para as profundidades de 80,100 e $250 \mathrm{~cm}$ o coeficiente de Nash ficou próximo de 0,5 mostrando uma aderência e confiabilidade razoável entre os dados medidos e calculados. Por fim, se o coeficiente for menor que 0 , o coeficiente indica que o modelo foge tanto da representatividade dos dados observados, quanto da sua média e o modelo não servirá para representar a situação para a qual foi produzido.

\section{CONCLUSÕES}

O solo da área tem textura areno-argilosa em todo perfil estudado, média a moderada porosidade com o menor valor de 39,3\% nas camadas mais superficiais e maiores valores, acima de $45 \%$ para as camadas a partir de $40 \mathrm{~cm}$, pois após essa profundidade obtiveram-se porosidades muito semelhantes e maiores que
$40 \%$. Em todas as curvas de retenção de água as umidades dos platôs de saturação e intermediário crescem com a profundidade. No entanto, a amplitude de valores entre os platôs de saturação e intermediário permanece aproximadamente a mesma e em torno de $25 \%$ independente da profundidade.

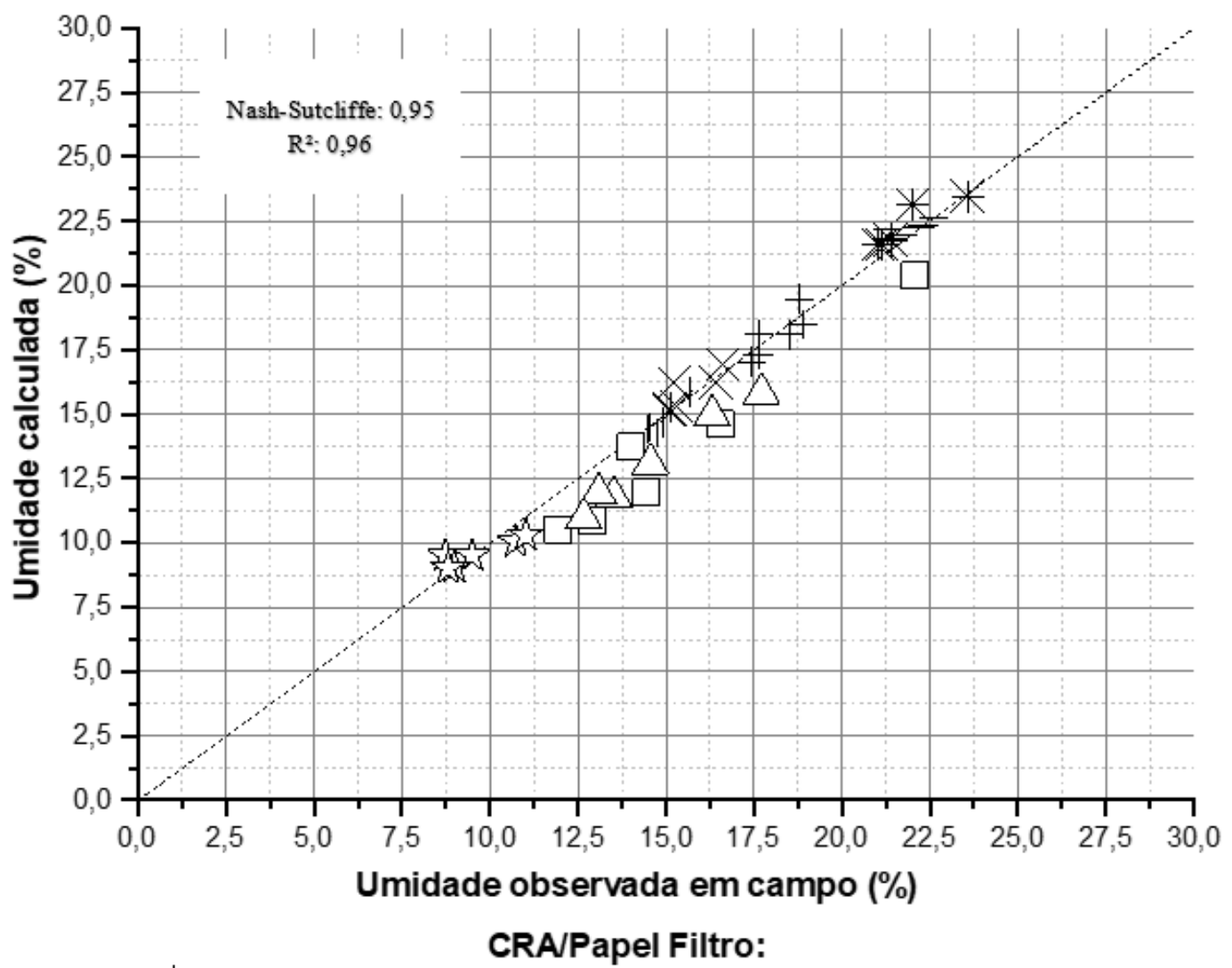

Legenda:

GF-CH $\triangle$ GF-M\&O 次 DVG-ASTM | MU-CH $>$ DVG-M\&O + GF-M\&O - BD-ASTM 米 BD-ASTM $\square$ GF-CH = Gitirana Jr. e Fredlund (2004) e calibração de Chandler et al. (1992) de 0 a $40 \mathrm{~cm}$ de profundidade; $\triangle \mathrm{GF}$

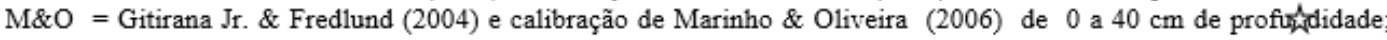
DVG-ASTM = Duplo van Genuchten sem restrição de parâmetros e calibração da ASTM (1992) de 40 a $100 \mathrm{~cm}$ de profundidade; $\mathrm{MU}-\mathrm{CH}=$ | van Genuchten com restrição de parâmetros de Mualen (1976) e calibração da Chandler et al. (1992) de 40 a $100 \mathrm{~cm}$ de profundidade; X DVG-M\&O = van Genuchten sem restrição de parâmetros e calibração de Marinho \& Oliveira (2006) de 40 a $100 \mathrm{~cm}$ de profundidade; + GF-M\&O = Gitirana Jr. \& Fredlund (2004) e calibração de Marinho \& Oliveira (2006) de 100 a $180 \mathrm{~cm}$ de profundidade; - BD-ASTM = van Genuchten com restrição de parâmetros de Bourdine (1953) e calibração da ASTM (1992) de 180 a $250 \mathrm{~cm}$ de profundidade; $*$ BD-ASTM = van Genuchten com restrição de parâmetros de Bourdine (1953) e calibração da ASTM (1992) de 180 a $250 \mathrm{~cm}$ de profundidade.

Figura 3 - Relação entre a umidade calculada pelas CRAs escolhidas da tabela 6 e as umidades medidas em campo. 
Além disso, as formas das CRAs da camada superficial, para todos os modelos e calibrações, possuem um platô intermediário inclinado, quase inexistente, diferente dos daqueles de outras profundidades, os quais são pronunciados. A escolha da CRA seguiu o melhor resultado dos coeficientes de determinação propostos $\mathrm{R}^{2}$, Nash-Sutcliffe, correlação quadrática de determinação e dos erros absolutos que entre elas foram menores que $11 \%$ de umidade. Logo, para a modelagem, optou-se pela escolha das CRAs como representado na Tabela 6, porém, salientase aqui que erros de $10 \%$ de umidade em teores de água reais que variam entre 10 a $40 \mathrm{~cm}^{3} \cdot \mathrm{cm}^{-3}$ são erros aceitáveis para a determinação da hidrodinâmica estudada, dado ao fato que a pesquisa trabalha com as diferenças de umidade no tempo e na profundidade. As umidades e pressões ajustadas às calibrações de papel filtro tiveram $R^{2}$ maiores que 0,93 indicando boa representatividade entre as pressões e as umidades do solo no perfil estudado. Entre as oito CRAs selecionadas com dados experimentais, 5 delas apresentaram ajustes razoáveis com $R^{2}$ acima de $0,8(10 \mathrm{~cm} ; 30 \mathrm{~cm} ; 50$ $\mathrm{cm}$; $80 \mathrm{~cm}$; e, $250 \mathrm{~cm})$, outras $3(100 \mathrm{~cm} ; 150 \mathrm{~cm}$ e $200 \mathrm{~cm}$ ) com $R^{2}$ regulares de 0,5 a 0,8. Já para os coeficientes de Nash-Sutcliffe, 5 delas apresentaram valores razoáveis entre 0,5 a 0,7 $(10 \mathrm{~cm} ; 50 \mathrm{~cm} ; 80 \mathrm{~cm} ; 100 \mathrm{~cm}$; e, $250 \mathrm{~cm}), 3$ delas coeficientes regulares de 0,1 a $0,5(30 \mathrm{~cm} ; 150 \mathrm{~cm}$; e, $200 \mathrm{~cm}$ ). Apesar do EAPM das umidades não ultrapassarem 11,07\% volume/volume, os ajustes demonstram que podem não predizer a umidade corretamente, em relação a tensão matricial real em campo das profundidades de $30 \mathrm{~cm}$ e $200 \mathrm{~cm}$ sem uma nova avaliação e refino do estudo.

Para as outras profundidades as curvas têm boa representatividade com razoável precisão. Sugere-se que a utilização com segurança das CRAs para a região de São Carlos e solos com características semelhantes, seja realizada para aquelas de até profundidade de $60 \mathrm{~cm}$ que é normalmente a faixa usual de instalação de tensiômetros para culturas de raízes fasciculadas de plantas, tais como cana-de-açúcar e milho, desde que se façam a validação das umidades. Para profundidades a partir de $60 \mathrm{~cm}$ de profundidade devem-se fazer testes de campo para validação da umidade antes de se utilizar as umidades e sugerem-se que se utilizem tensiômetros de punção digitais para uma melhor precisão.

\section{AGRADECIMENTOS}

À Financiadora de Estudos e Projetos do Ministério da Ciência e Tecnologia (FINEP), ao Centro Nacional de Pesquisas (CNPq), à Coordenação de aperfeiçoamento de Pessoal de Nível Superior (CAPES) e ao Programa de Pós Graduação em Engenharia Urbana (UFSCar).

\section{REFERÊNCIAS}

ASSOCIAÇÃO BRASILEIRA DE NORMAS TÉCNICAS ABNT. NBR 6457. Preparação de amostras de solo para ensaio de compactação e ensaio de caracterização: método de ensaio. Rio de Janeiro, 1986.

ASSOCIAÇÃO BRASILEIRA DE NORMAS TÉCNICAS ABNT. NBR 6508. Grãos que passam na peneira de $4,8 \mathrm{~mm}$. Determinação da massa específica: método de ensaio. Rio de Janeiro, 1984.

ASSOCIAÇÃO BRASILEIRA DE NORMAS TÉCNICAS ABNT. NBR 7181. Análise granulométrica de solos. Rio de Janeiro, 1982.

ASTM. Standard test method for measurement of soil potential (suction) using filter paper. (D. 5298-92). Annual Book of ASTM Standards, v. 15.09. 1992.

BICALHO, K.V.; CORREIA, A.G.; FERREIRA, S.; FLEUREAU, J.M.; MARINHO, F.A.M. The use of filter paper method for matric suction measurement of an unsaturated compacted silty sand. In: SIMPÓSIO BRASILEIRO DE SOLOS NÃO SATURADOS, 6, Salvador, 2007. Anais... Salvador, Associação Brasileira de Mecânica dos Solos e Engenharia Geotécnica. 2007. p. 215-219.

BROOKS, R. H. \& COREY, A. T. Hydraulic properties of porous media. Hydrology Paper No. 3, Colorado State Univ., Fort Collins, CO. 1964.

BULUT, R. A reevaluation of the filter paper method of measuring soil suction. Lubbock, 1996. 89p. (Tese de Mestrado), Texas Tech University.
BURDINE, N.T. Relative permeability calculation from poresize distribution data. Trans. Am. Inst. Min., Metall. Pet. Eng., v. 198, p. 71-77, 1953.

CAMAPUM DE CARVALHO, J.; GITIRANA JR, G.F.N.; CARVALHO. E.T.L. (Org.). Tópicos sobre infiltração: teoria e prática aplicadas a solos tropicais. Brasília: Faculdade de Tecnologia, 2012. 644 p. (Série Geotecnia - UnB, v. 4).

CARDUCCI, C.E.; OLIVEIRA, G.C.; SEVERIANO, E.C.; ZEVIANI, W.M. Modelagem da curva de retenção de água de latossolos utilizando a equação duplo vangenuchten. R. Bras. Ci. Solo, v. 35, p. 77-86, 2011.

CHANDLER, R.J. \& GUTIERREZ, C.I. The filterpaper method of suction measurement. Geotechnique, v. 36, n. 2, p. 265-268, 1986.

CHANDLER, R.J.; CRILLEY,M.S.; MONTGOMERY-SMITH, G.A low-cost method of assessing clay desiccation forlow-rise buildings. Proc. Instn. Civ. Engrs Civ. Engng. v. 92, May. P. 82-89, 1992.

CHILDS, E.C. \& COLLIS-GEORGE, N. The permeability of porous materials. Proc. R. Soc. London Ser. A. 201, p. 392405, 1950.

CORNELIS, W.M., KHOSI, R.; HARTMANN, M.; VAN MEIRVENNE, B.; DE VOS. Comparison of unimodal analytical expressions for the soil-water retention curve. Soil Sci. Soc. Am. J. v. 69, p. 1902-1911, 2005. doi:10.2136/sssaj2004.0238 
DEXTER, A.R. \& BIRD, N.R.A. Methods for predicting the optimum and the range of soil water contents for tillage based on the water retention curve. Soil Till. Res., v. 57, p. 203-212, 2001.

DEXTER, A.R.; CZYŻ, E.A.; RICHARD, G. RESZKOWSKA, A. A user-friendly water retention function that takes account of the textural and structural pore spaces in soil. Geoderma, v. 143, p. 243-253, 2008.

DOURADO NETO, D; JONG VAN LIER, Q; REICHARDT, K; VAN GENUCHTEN, M.TH; METSELAAR, K; NIELSEN, D.R. Alternative Analytical Expressions for the General van Genuchten-Mualem and van Genuchten-Burdine Hydraulic Conductivity Models. Vadose Zone Journal. J. v. 10, p. 618623, 2011. Doi:10.2136/vzj2009.0191

DURNER, W. Hydraulic conductivity estimation for soils with heterogeneous pore structure. Water Resoor. Res., v. 30, p. 211-223, 1994.

DURNER, W. Predicting the unsaturated hydraulic conductivity using multi-porosity water retention curves. In: M.T. VAN GENUCHTEN, FT. LEIJ; L.J. LUND (Eds), Proceedings of the International Workshop, Indirect Methods for Estimating the Hydraulic Properties of Unsaturated Soils. University of California, Riverside, p. 185-202, 1992.

FARREL, D.A. \& LARSON, W.E. Modeling the pore structure of porous media. Water Resour. Res., v. 8, p. 699-706, 1972.

FREDLUND, D.G. \& RAHARDJO H. Soil mechanics for unsaturated soils. Wiley \& Sons, New York. 1993.

FREDLUND, D.G. \& XING, A. Equations for the soil-water characteristic curve. Canadian Geotechnical Journal, [s.l.], v. 31, n. 3, p. 521-532, 1994

GARDNER, R. A method of measuring the capillary tension of soil moisture over a wide moisture range. Soil Sci. v. 43, p. $277-$ 283, 1937.

GARDNER, W.R. Representation of soil aggregate-size distribution by a logarithmic-normal distribution. Soil Sci. Soc. Am. Proc. V. 20, p. 151-153, 1956.

GERKE, H.H. \& VAN GENUCHTEN. M.TH. A dual-porosity model for simulating the preferential movement of water and solutes in structured porous media, Water Resour. Res., v. 29, p. 305-319, 1993a.

GIAROLA, N.F.B.; SILVA, A.P. \& IMHOFF, S. Relações entre propriedades físicas e características de solos da região sul do Brasil. R. Bras. Ci. Solo, v. 26, p. 885-893, 2002.

GITIRANA JR., G.F.N. \& FREDLUND, D.G., Soil-water characteristic curve with in-dependent properties. Journal of Geotechnical and Geoenvironmental Engineering, [s.l.], v. 130, n. 2, p. 209-212, 2004.

GONÇALVES, A. R. L. Geologia Ambiental da área de São Carlos. São Paulo, 1986. Tese (Doutorado em Geologia Geral e de Aplicação) - Instituto de Geociências, Universidade de São Paulo.

HILLEL, D. Fundamentals of soil physics. New York, Academic Press, 1980. 413 p.

KHALEEL, R. \& RELYEA. J.F. Evaluation of van GenuchtenMualem relationships to estimate unsaturated hydraulic conductivity at low water contents. WaterResour. Res., v. 31, p. 2659-2668, 1995.

LIBARDI, P.L. Dinâmica da água no solo. Piracicaba: Editado pelo autor, 1995. 497 p.

LIKOS, W.J. \& LU, N. Filter paper technique for measuring total soil suction.Transportation Research Record 1786, Paper n. 02-2140, p. 120-128, 2002.
MALLANTS, D.; MOHANTY, B.P.; VERVOORT, A.; FEYEN, J. Spatial analysis of saturated hydraulic conductivity in a soil with macropores. Soil Technol. v. 10, p. 115-132, 1997.

MARINHO, F.A.M. \& OLIVEIRA, O.M. The filter paper method revised. ASTM geotechnical testing journal, USA, v. 29, n. 3, p. 250-258, 2006.

MUALEM, Y. A new model for predicting the hydraulic conductivity of unsaturated porous media. Water Res. Res., v. 12, p. 513-522, 1976.

NIELSEN, D.R.; VAN GENUCHTEN, M.T.; BIGGAR, J.W. Water Flow and Solute Transport Processes in Unsaturated Zone, Water Resources Research, v. 22, n. 9, p. 89S-108S, 1986.

REICHARDT, K. Dinâmica da matéria e da energia em ecossistemas. Piracicaba, SP.: ESALQ/USP., Depto. Física e Meteorologia, 505 p., 1996.

RICHARDS, S.J. Soil suction measurements with tensiometers. In: Methods of Soil Analysis, Monograph No. 9, p. 153-163. Am. Soc. Agron., Madison, WI. 1965.

ROTH, K. Soil Physics. Lecture Notes. Institute of Environmental Physics, Heidelberg University, 2011. 351 p.

RUAS LUCAS, J.F.L.; TAVARES, M.H.F.; CARDOSO, D.L.; CÁSSARO, F.A.M. Curva de retenção de água no solo pelo método do papel filtro. R. Bras. Ci. Solo, v. 35, p. 1957-1973, 2011.

ŠIMU゚NEK, J. \& VAN GENUCHTEN, M. TH. Modeling nonequilibrium flow and transport with HYDRUS, Vadose Zone Journal, doi:10.2136/VZJ2007.0074, Special Issue “Vadose Zone Modeling”, v. 7, n. 2, p. 782-797, 2008.

ŠIMU゚NEK, J.D.; JACQUES, J.W.; HOPMANS, M.; INOUE, M.; FLURY, M., VAN GENUCHTEN. TH. Solute Transport During Variably-Saturated Flow - Inverse Methods, In: Methods of Soil Analysis, Part 1, Physical Methods, Chapter 6.6, Eds. J. H. Dane and G. C. Topp, Third edition, SSSA, Madison, WI, p. 1435-1449, 2002.

SOARES, P.C.; LANDIM, P.M.B.; FULFARO, V.J.; SOBREIRO NETO, A.F. Ensaio de Caracterização do cretáceo no Estado de São Paulo. Rev. Bras. Geoc., v. 10, p. 177-185, 1980.

USA - Tensiometer Use in Irrigation Scheduling. By Mahbub Alam and Danny H. Rogers. Kansas State University Agricultural Experiment Station and Cooperative Extension Service, Manhattan, KS. 6 p. 1997.

VAN GENUCHTEN, M. TH. A closed-form equation for predicting the hydraulic conductivity of unsaturated soils. Soil Sci. Soc. Am. J. v. 44, p. 892-898, 1980.

VEREECKEN, H. Estimating the unsaturated hydraulic conductivity from theoretical models using simple soil properties. Geoderma v. 65, p. 81-92, 1995.

YATES, S.R., M.TH. VAN GENUCHTEN, A.W. WARRICK, AND F.J. LEIJ. Analysis of measured, predicted, and estimated hydraulic conductivity using the RETC computer program. SoilSci. Soc. Am. J. v. 56, p. 347-354, 1992.

Submetido em 7 de agosto de 2019 Aceito para publicação em 11 de agosto de 2020 